\title{
La cuestión democrática en América Latina: algunos temas y problemas *
}

\author{
Agustín Cueva
}

\section{Introducción}

En su libro Por que democracia, Francisco C. Weffort (1986, p. 61), afirma que "si los años 50 son los años de constitución del desarrollismo como valor general, (...) los años 70 y los 80 son los de constitución de la democracia como valor general". Y el autor tiene razón, con la única aclaración de que no es la primera vez que tal cosa ocurre, como fenómeno generalızado, en Amérıca Latına. Muchos recordarán, por ejemplo, que la democracia fue asumida como valor universal altamente movilizador durante el periodo conocido como de la segunda posguerra; esto es, en el lapso comprendido entre el momento inmediatamente anterior a la derrota del nacifascismo (desde 1944 aproximadamente) y aquel punto de inflexión determinado tanto por la guerra fria (ıniciada en 1947), cuanto por el declive del boom económico ligado a dicha posguerra (declive que se torna crítico a mediados de los años 50). Esto, para no hablar de aquellos paréntesis democráticos, a veces prolongados; $o$, por lo menos, de esos destellos de democracia que casi todos nuestros países han atisbado fugazmente, incluso en áreas tan críticas como las de Centroaméruca o el Carbe. En algunos casos, tales experiencias democráticas parecieran haber sido bastante más intensas y dınámicas de lo que hoy solemos imaginar. Con referencia al Brasil de comienzos de los años 60 , por ejemplo, Daniel Aarão Reis Filho formula la reflexión siguiente:
'Es interesante constatar que la coyuntura de 1961 a 1964 registra el nivel de democratización más elevado de nuestra historia republicana; sólo hasta entonces los trabajadores conquistaron efectivamente una posición inédita y realmente se colocaron como interlocutores. Por más que uno pueda formular reservas sobre la consistencia de las propuestas politicas o sobre las formas de lucha o la organización interna del movimiento social de los trabajadores urbanos y rurales, el hecho es que hubo en esta coyuntura un movimiento inédito. Trátase, por lo demás, de un periodo poco estudiado o estududo de manera injusta, lo que tal vez se deba a que, por razones enteramente diferentes, tanto el PCB como la 'nueva izquierda' surgida después de 1964, decidierono pretendieron decidir olvidarse de las experiencias de este periodo." (GARCIA, 1986, p. 20-1.)

Sea de esto lo que fuere, la verdad es que no sólo en el movimiento real de la historia, sıno también en el de las ideas, la cuestión de la democracia jamás dejó de plantearse en la Latinoamérıca contemporánea. En este sentido, no es un azar que uno de los libros fundamentales de nuestra moderna sociología - surgida en el turbulento clima de los años $60-$ se llamase precisamente La democracia en México: su autor, como todos lo saben, es Pablo González Casanova (1965)I I Y tampoco es fruto de la casualidad el hecho de que en esa especie de vademécum de la sociología

\footnotetext{
"El presente ensayo ha sido escrito como parte de mis actividades de profesor visitante del Instituto de Estudos Avançados de la Universidad de Säo Paulo (USP), cuyo gentil auspicio agradezco. Mayo-junio de 1987.

I Desde entonces hasta ahora (1987) la obra ha tenido 17 ediciones, la ultima con un tiraje de 10 mil ejemplares.
} 
radical latinoamericana $y$ latinoamericanista, que James Petras y Maunce Zeitlin publicaron a finales de la década de los 60 con el título original de Latin America, reform or revolutions? (1968), la interrogación sobre la democracia (o sobre su ausencia) en la región, también estuviese presentell.

De todos modos, la búsqueda de democracia no es algo ajeno a la cultura latinoamericana, a sus tradiciones, valores y luchas. Antes que a una supuesta verdad revelada únicamente en los años 70, antes que a una suerte de epifania proveniente de los tex tos de algún Castoriadis o un Leffort, la democracia en América Latına se asemeja más bien al mar del famoso poeta francés: "toujours recommencée"... Y en este sentido guarda, como es natural, un estrecho parangón con otro de nuestros grandes temas y problemas: el de la modernidad. Desde hace por lo menos un siglo que venimos entrando vertiginosamente en ésta (no se olvide que el movimiento modernista hispanoamericano, por ejemplo, data de finales del siglo pasado), de la misma forma en que venimos transitando desde entonces hacia la democracia. Sólo que una especie de maldición o hechızo pesa sobre el subcontinente, haciendo que estos dos preciados bienes terminen siempre por escapársenos.

No obstante, serfa absurdo desconocer que el problema de la democracia (como el de la propia modernidad), se plantea ahora en términos nuevos, diferentes de los de hace 20 ó 40 años. El contexto internacional ha cambiado y la fisonomía de nuestros países también; tenemos una experiencia política mayor aunque no necesariamente más alentadora; nuestras pautas culturales han sufrido muchas modificaciones, aunque quizás menos de lo que solemos imaginar. $Y$ es verdad que, así como el tema recurrente de los años 50 y 60 fue el del desarrollo, el asunto privilegiado en la actualidad es el de la democracia. Con una similitud más: tal como en los años 50 parecía un crimen, a la par ético y teórico, preguntar de qué tıpo de desarrollo se estaba finalmente hablando ( iquién no sabía que el desarrollo era el desarrollo, puro y sobre todo sin calificativos!), asimısmo ahora parece de mal gusto. por decir lo menos, preguntar hacia qué tipo de democracia se está exactamente avanzando. En uno como en otro caso nos encontramos frente a anhelos y posibilidades legítimos y reales, pero también, no lo ocultemos, nos confrontamos a un discurso que busca convertirlos en especies de entelequias aristotélicas, que ningún proceso histórico concreto sería capaz de determinar. Aquellos procesos sin embargo existen y estas determinaciones también, $y$ es mejor no asumir frente a ellos la actitud del avestruz, aunque sólo fuese con el fin de evitar sorpresas como las que nuestro propio desarrollo ha tenido a bien depararnos hasta hoy.

\section{Contextos de la "Transición"}

Lo curioso, en todo esto, es que prácticamente ninguno de los millares de artículos que en los últimos años se han escrito sobre el tema de la llamada transición a la democracia abordan el contexto mundial, regional $y$ nacional en el que ella viene ocurriendo. Y hablo de artículos, que

II Particularmente los articulos de Merle Kling y Maurice Zeitlin. 
Los vientos que soplan actualmente en

Occidente sin duda no son los más

progresistas; son más bien radicalmente antisocialistas $y$ antitercermundistas,

por mucho que los

teóricos occidentales traten a veces de dorar aquella pildora con el discurso suave, elegante y casi escéptico, relativo a la posmodernidad. no de libros, porque una de las expresiones más elocuentes de la crisis del pensamiento latinoamericano en la década actual consiste precisamente en la incapacidad de plasmar nuestras inquietudes y proyectos en obras de grande o por lo menos mediano aliento. Pero éste no es el tema del presente ensayo, así que volvamos a la cuestión de aquellos contextos.

Tenemos, para comenzar, un dato crucial, en torno del cual pareciera haberse establecido una verdadera conspiración del silencio: nos referimos a la profunda derechización de Occidente, notoria no sólo a nivel político (Reagan, Thatcher, Nakasone, Kohl, Waldheim etc.), $y$ económico-social (neoliberalismo a ultranza, desmantelamiento del welfare state etc.), sino también a nivel ideológico-cultural, como en otro lugar lo hemos tratado de demostrar ${ }^{1}$. Los vientos que soplan actualmente en Occidente sin duda no son los más progresistas; son más bien radicalmente antisocialistas $y$ antitercermundistas, por mucho que los teóricos occidentales traten a veces de dorar aquella píldora con el discurso suave, elegante y casi escéptico, relativo a la posmodernidad2.

Un segundo dato en el que poco se insiste es el de que los paises imperialistas, que ciertamente no están en recesión en este momento, registran, en cambio, tasas muy modestas de crecimiento económico 3 . Ello les impide resolver problemas como el de su propia desocupación (cerca de 20 millones de parados sólo en Europa Occidental), a la par que los vielve xenófobos (odio a los emigrados de la periferia que están quitando el trabajo a los nacionales de Europa, Estados Unidos y Japón), e inflexibles en sus relaciones económicas con los países subdesarrollados, con todas las consecuencias políticas que ello implica, dada la profundización de nuestra dependencia. Y es que, como observa Jair Pereira dos Santos con palabras sencillas pero pertinentes, la propia posmodernidad tiene su derecho pero también su envés:

"La riqueza postindustrial es en gran parte financiada por los paises en vias de desarrollo, puesto que el capitalismo avanzado se ha vuelto transnacional. Vienen para acá las industrias pesadas y sucias (acero, automóviles); permanecen allä las ligeras y limpias /electrónica, comunicaciones). Su control social puede ser soft / blando, mediante la seducción), pero el nuestro tiene que ser hard (moderno, duro, policial, a base de garrotazos)." (SANTOS, 1986, p. 100-1.)

En tercer lugar, está la crisis económica de América Latina,

1 Cf. Agustin Cueva en: "Tiempos conservadores: América Latina en la derechización de Occidente" (1987).

2 Cf. a este respecto, p.e., Jean.François Lyotard en: "La condición pasmoderna" (1984), y 0, Giannt Vattino: "El fin de la modemidad. Nihilismo y hermenéutica en la cultura posmodema" (1986). Para un punto de vista más critico puede consultarse el articulo de Fredric Jameson: "Pos-modernidade e soctedade de consumo" (1985).

3 Cf. Banco Mundial/Fundação Getülio Vargas: Relatório sobre o desenvolvimento mundial, 1986 (São Paulo), donde se habla de una "ttmida recuperaçāo" de la economia occidental. Según estimaciones del propio Reagan (19-X-87), la economia estadounidense crecerd en un $2.5 \%$ en 1987.

estudos AVANÇADOS 
paradigmáticamente expresada en el voluminoso endeudamiento ex terno que ahoga a todos nuestros países. Aquí nos limitaremos a observar que nadie atisba hasta ahora salida alguna para dicha crisis, sobre todo a raíz del estrepitoso fracaso del Plan Cruzado brasileño. Un preinforme de la CEPAL sobre el panorama económico de América Latina en 1987 prevé que el producto interno bruto de la región crecerá a un ritmo significativamente inferior al de 1986 y que, "en todo caso, las tasas de crecimiento (de la mayoria de los paises del área) aparentemente convergerán a niveles moderados, si no mediocres"'(EL DIA, 1987, p. 22).

Por último, no hay que olvidar algo que pareciera ser la evidencia misma, pero que a pesar de ello termina por sumergirse en la más profunda amnesia: las fuerzas de izquierda, propulsoras de cambios estructurales verdaderos, sufrieron en los años $60 \mathrm{y}$ sobre todo en los 70 una severa derrota a manos de las dictaduras militares en un gran número de países, especialmente sudamericano, hecho que transformó completamente el panorama político de la región. En particular $-y$ en ese orden de magnitud de la derrota - hay que mencionar los casos de Argentina, Brasil, Bolivia e Uruguay (Chile, donde ni la más feroz represión pinochetista consigue doblegar a la izquierda, constituye desde luego una excepción).

Como dice el sociólogo Augusto Varas, aunque desde una perspectiva muy distinta de la nuestra, tales dictaduras consiguieron "la marginalización y/o el aislamiento de las fuerzas antisistema" (antisistema capitalista se entiende), el "asilamiento de ideologias de corte fundamentalista" (sic), la "derrota del
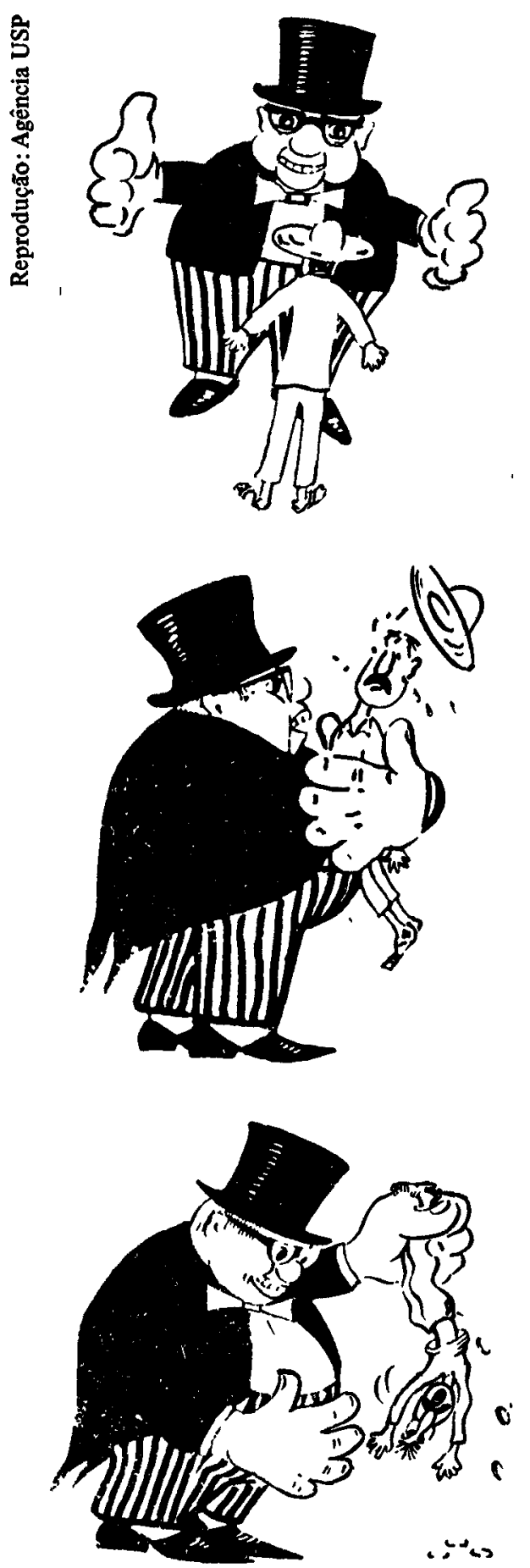

En tercer lugar, está la crisis económica de América Latina, paradigmáticamente expresada en el voluminoso endeudamiento externo que ahoga a todos nuestros países. Aqur nos limitaremos a observar que nadie atisba hasta ahora salida alguna para dicha crisis, sobre todo a rafz del estrepitoso fracaso del Plan Cruzado brasileño. 
ideologismo" (hay que suponer que el de izquierda) y "la emergencia de perspectivas más pragmáticas e institucionalistas"(VARAS, 1986). En definitiva $-y$ esto es obviamente una conclusión nuestra y no de Varas esas dictaduras realizaron algo que perfectamente podría ser el programa de restauración político-institucional de la administración Reagan.

A este nítıdo triunfo de las fuerzas prosistema (burguesía, militares, actıtud pragmática en vez de crítica, marginamiento de las ideologías de izquierda), es a lo que denominamos condiciones conservadoras de transición. Y ello, porque no se trata de un simple cambio de nuestra cultura politica (como reza el eufemismo en boga), sino, esencialmente, de un cambio muy marcado en la correlación de fuerzas socio-politicas.

\section{Principales Posiciones Teóricas}

En la América Latina de hoy encontranos, como es natural, las más diversas posiciones

teórico-políticas con respecto al problema de la democracia, dentro de una constelación 1deológica que además varía sıgnificativamente en razón del país concreto al que nos refiramos. Empero, creemos no volentar demasiado la realidad si agrupamos aquellas posiciones en cuatro rubros principales.

Existe, en primer lugar (y cada día con mayor fuerza), una corriente de pensamiento conservadora, encabezada a nivel continental por dos escritores de enorme prestigio: Mario Vargas Llosa y Octavio Paz. Lo medular de sus ideas sobre el tema se halla recopilado en el libro América Latina: desventuras de la democracia, escrito con la colaboración de dieciocho intelectuales de diferentes paises de la región. En México, dicha corriente se agrupa en torno de la revista Vuelta, dirigida por el propio $\mathrm{Paz}$, y tiene su mejor exponente en la materia en la persona del politólogo Enrique Krauze. Su libro Por una democracia sin adjetivos, que adquirió súbita notoriedad en 1986, ligado a la oleada derechizante que se formó en torno del Partido de Acción Nacional (PAN), revela con su sólo título una de las principales aspiraciones del conservadurismo latinoamericano: que la democracia no reciba adjetivos; es decir, que sea concebida como una esfera exclusivamente politica, carente de determinaciones exteriores y desvinculada de todo sustrato económico y de cualquier dimensión hegemónica. En palabras de Krauze:

"La democracia busca la libertad y la igualdad polfticas, igualdad de participación, influencia y vigilancia sobre decisiones políticas En este sentido, la democracia es un objetivo distinto de otros, no menos importantes: igualdad material, bienestar, paz, seguridad, orden, fraternidad etc. . ."(KRAUZE, 1986, p. 81.)

Prácticamente desconocido fuera de Méxıco, Krauze fue sin embargo canonizado por Mario Vargas Llosa como uno de los poquísimos autores latinoamericanos (junto con Gabriel Zaid) que han superado " $\mathrm{el}$ oscurantismo ideológico" y "han producido espléndidos trabajos de actualidad politica y económica" (BENEDETTI e VARGAS LLOSA, 1984, p. 50). Opinión que tal vez no revele mayor competencia en la materia por parte de Vargas Llosa, aunque sí testimonia sobre la 
agresividad y el desparpajo con se maneja y pontifica el pensamiento conservadorlil.

Si la tesis de Krauze se centra en la defensa de una democracia sin adjetivos, opiniones como la del profesor Albert $O$. Hirschman insisten, en cambio, en la democracia sin condiciones. Cito a continuación un pasaje de un conocido artículo suyo:

"Una manera especialmente perniciosa de reflexionar en el fortalecimiento de la democracia (porque puede ayudar a debilitarla, como ha sucedido en el pasado) consiste en enumerar las condiciones estrictas que han de satisfacerse para que la democracia exista: por ejemplo, que debe haber un crecimiento económico vigoroso y una mejor distribución del ingreso; que la autonomia nacional debe afïrmarse. .." (HIRSCHMAN, 1986, p. 28.) $)^{\mathrm{IV}}$

Posición que no puede ser más expresiva de cómo, para el pensamiento conservador, no s6́lo la tradicional tesis socialdemocrata de una democracia adjetivada (social) se ha tornado perniciosa, sino que igual ocurre con los más clásicos planteamientos de la CEPAL, como los que Hirschman rebate. Sé muy bien que Hirschman no es un autor latinoamericano, mas no es por azar que dicho texto ha sido tan difundido en nuestros países.

En segundo lugar tenemos aquella corriente que tiende a ser la predominante en el plano teórico, por la sencilla razón de que ya lo es en el plano político, al menos en Sudamérica: nos referimos, como es obvio, a la corriente socialdemócrata. No se olvide, por lo demás, que en este momento ella controla por lo menos el 80 por ciento del aparato burocrático encargado de orientar la producción de nuestras ciencias sociales.

Esta tendencia, de la que Fernando Henrique Cardoso es el exponente intelectual más brillante en el continente, ha producido infinidad de textos, de los cuales señalaremos dos antologías, a título de ejemplo: Autoritarismo y alternativas populares en America Latina4 y Caminos de la democracia en América Latinas. El pensamiento de los autores socialdemócratas no es desde luego homogéneo; pero es un hecho que hoy el sector más productivo y militante respecto del tema que venimos analizando proviene,

III En el campo de las ciencias sociales, ese pensamiento ha sido casi nulo o extremadamente pobre, sobre todo en los patses de lengua española. Se comprende por eso la euforia con que ha sido recibido el libro $\mathbf{g}$ otro sendero, de Hernando De Soto, con prólogo de Mario Vargas Llosa (Ed. Oveja Negra, Bogoth, Colombia, 1987; la edición peruana apareció un año antes). El trabajo de Hernando De Soto tiene sin duda una calidad y una consistencia mucho menores de lo que sus coidearios le atribuyen, pero ciertamente estd a kilometros de distancia de las mediocridades a que nos tenta acostumbrados, por ejemplo, un Carlos Rangel ( $\boldsymbol{B}$ tercermundismo, Del buen salvaje al buen revolucionario, etc.).

IV Fue publicado en portugués por Novos estudos CEBRAP, número 15, julho de 1986, con el titulo de "A democracia na América Latina: dilemas".

4 De varios autores, Ediciones FLACSO, Colección 25 aniversario, San José, Costa Rica, 1982.

5 Fundación Pablo Iglesias (varios autores), Editorial Pablo Iglesias, Madrid, 1984.

Cf. especialmente el cap. VI, dedicado a "La polttica". 
desafortunadamente, de las posiciones menos progresistas. Localizado en el Cono Sur, especialmente en Chile y Argentina, su actitud está muy influida por tres órdenes de factores:

a) En el caso chileno, dicho sector se enfrenta a una alternativa marxista vigente, a la que combate con esmero.

b) En el caso argentino, tiende a atribuir la frustración histórica del país a un extremismo que, sin embargo, fue la última expresión y no la causa de problemas más profundos que sistemáticamente se evita analizar $\mathrm{V}$.

c) En ambos casos, la corriente socialdemócrata está integrada por un núcleo de ex-marxistas, incluso ex-comunistas.

Esta constelación de factores lleva a que trabajos como los de Tomás Moulián, Angel Flisfich, Manuel A. Garretón, José Aricó, Juan Carlos Portantiero o Marcelo Cavarozzi6, además de limitarse a la defensa de concepciones estrechamente liberales de la democracia, estén impregnados de un reiterado antimarxismo, dentro de un proyecto de desmontar hasta en sus últimos detalles y consecuencias la visión de América Latina que la izquierda revolucionaria - e incluso la reformista o populista construyeron a lo largo de este siglo.

La tercera corriente que mencionaremos es la eurocomunista, con respecto a la cual hay poco que decir. Ella no dispone de ningún aparato institucional tan impresionante como el que sirve de infraestructura a los conservadores y a los socialdemócratas, ni está en la cresta de una onda política ascendente, cual es el caso de estos últimos en América Latina y de los primeros en el Occidente en general.

Por lo demás, en regiones como América Central el eurocomunismo carece de espacio, en la medida en que el lado izquierdo está ocupado por las diferentes tendencias revolucionarias, al mismo tiempo que en el Cono Sur parece condenado a ser una variante pobre y superada de la socialdemocracia.

En tales condiciones, la vertiente de inspiración eurocomunista ha contribuido al debate más por el valor individual de algunos de sus exponentes que por el vigor como corriente teórico-política. Me limitaré a citar como ejemplo dos libros, tan brillantes cuanto controvertibles: La democracia ausente, del mexicano Roger Bartra (México, 1986), y A democracia como valor universal e outros ensaios, de Carlos Nelson Coutınho (Rio de Janeiro, $2^{\mathrm{a}}$ ed., 1984.)

Queda, en cuarto lugar, la corriente que denominaré del pensamiento radical (antimperialista y en general marxista), ligada al movimiento revolucionario latinoamericano. A ella pertenecen, para comenzar, los trabajos directamente derivados de la experiencia centroamericana, que son

$\mathrm{V}$ Al menos por la mayor parte de los sociblogos argentinos; lo cual no impide que haya estudios de gran lucidez sobre la Argentina contemporánea, como el del investigador inglés Richard Gillespie en: "Soldados de Perón. Los Montoneros" (1987).

6 Cf., p. e., A. Flisfich, N. Lechner y T. Moulián: "Problemas de la democracia y la politica democrática en A mérica Latina", en A. Flisfich et alii:Democracia y desarrollo en América Latina (1985), y o M. Cavarozzi: Autoritarismo y democracia (1983). 
innumerables. A simple título de ejemplo mencionaremos La revolución en Nicarágua. Liberacibn nacional, democracia popular y transformacion económica (México, 1985), libro colectivo que recoge críticamente la experiencia de la revolución mencionada, o Perfiles de la revolución sandinista, de Carlos $\mathbf{M}$. Vilas (Cuba, 1984). Solo que este tipo de trabajos son frecuentemente discriminados dentro del debate sobre la democracia, en la exacta medida en que la ideología conservadora consigue imponer ciertos clisés como evidencias: "no puede haber revolución democritica, puesto que toda revolución es perversa", "no puede haber democracia revolucionaria ya que la democracia no tiene adjetivos". Aún así, dicha corriente radical sigue produciendo una vigorosa reflexión en muchos países, incluso fuera del área mencionada. Citemos, siempre en calidad de ejemplo, obras como El poder al pueblo, de Pablo González Casanova (México, 1986), o, para el caso brasilefio, los estudios de Octavio Ianni7 y Florestan Fernandes 8 , con menor repercusión interna, los últimos ensayos de Ruy Mauro Marini 9 .

Tales son, a nuestro parecer, las principales corrientes en vigor, con la necesaria aclaración de que ellas no configuran compartimientos rigurosamente estancos. Todas participan, aunque contradictoriamente, de un mismo espacio cultural, con un buen número de referencias comunes; en algunos casos, como el de la tendencia socialdemocrata y la eurocomunista, ellas se recortan como círculos secantes. $Y$ hay autores, muchas veces notables, que se ubican en la intersección de hasta tres de esas corrientes: las que acabamos de mencionar más la radical. Sería el caso, por ejemplo, de Francisco Weffort, si nuestra lectura de sus valiosos textos no nos engaña.

\section{La Crisis de Identidad}

En un artículo intitulado "Pacto social nos procesos de democratização: a experiencia latinoamericana", Norbert Lechner tuvo el acierto de plantear algunas cuestiones relativas al momento actual de América Latina que con frecuencia se dejan de lado o, lo que es más probable, ni siquiera se perciben con nitidez. El autor advierte que durante los affos de dictadura se produjo una "erosión de las identidades colectivas" (LECHNER, 1985 , p. 34), y que, por ende, la crisis que atravesamos consiste (además de todo lo que ya se sabe) en una "pérdida 0 , por lo menos, una renovación del significado de las identidades colectivas"'(Idem, p. 29). Luego apunta que hay una "crisis de sentido", para enseguida señalar que, por lo tanto, "la negociación relativa a las instituciones formales se basa,

7 Sobre el tema especlfico cf., p. e., "A nova república do Brazil", que aparecert en la edicion brasileña de Tiempos conservadores: América Latina en la derechización de Occidente, (ver nota 5), en prensa.

\section{Por ejemplo, o libro Que tipo de república (1986). América Latina en la derechización de Occtdente.}

9 Cf. p. e. su artlculo "A nova democracia latino-americana", en el periódico: Humanidades (1987). 
Para guienes no Is tengan presente, conviene recordar gue en 1976. por ejemplo, cast no exisía paŕs alguno de América

Latina libre de algum tipo de dictadura militar. con el agravante de que. incluso las dictaduras en cierto sentido progeststas, como las de Peri, Ecuador y

Honduras, habran virado ya a la derecha. Sólo a partir de 1977-78 las masas del continente comenzaron a recuperar la iniciativa, (. .). asi, en una producción de un sentido de orden" (Idem, p. 30). Finalmente concluye que:

"Si entendemos por democracia no sólo un sistema formal y nos referimos, en la perspectiva de la soberania popular, a la democratización como un proceso de subjetivación, entonces podriamos ver tal vez en la negociación un mecanismo de constitución de sujetos. "(Idem, p. 30.)

No sé si alguna vez en algún lugar de la tierra alguien consiguı́ constituir sujetos a través de la negociación, o sı ésta sirve más bien para adaptar los sujetos a condiciones estructurales dadas o, en la mejor de las hipótesis, para pactar algunos reacomodos $y$ afinamientos que faciliten tal adaptación. Más adelante volveremos sobre este tema; entre tanto, conviene destacar nuestro acuerdo con las demás observaciones de Lechner, de las que aprovecharemos para extraer nuestras propias conclusiones.

a) Es verdad que las dictaduras milıtares no sólo consiguieron

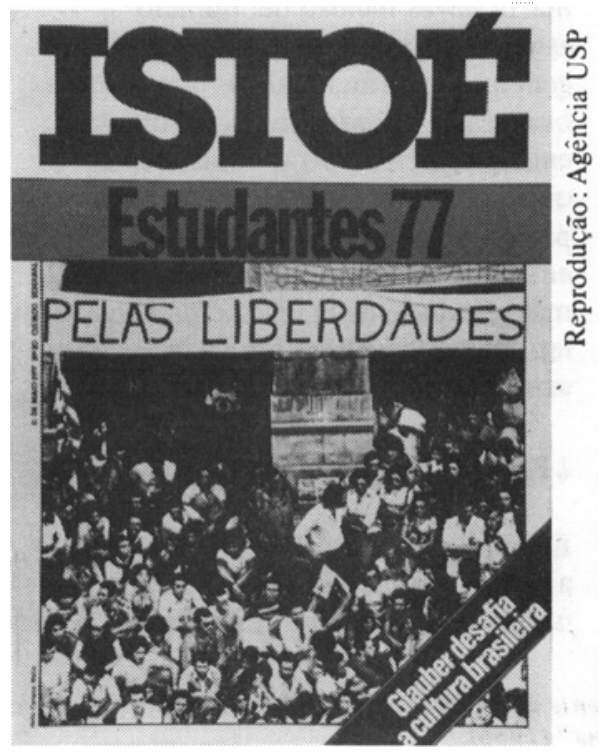

estudos AVANÇADOS desarticular - en mayor o menor grado, según el país del que se trate - las instituciones democráticas y las organizaciones políticas y parapolíticas de la izquierda, sino que además lograron erosionar las identidades colectivas de los actores derrotados. Y estos derrotados fueron, en el plano político, fundamentalmente dos: el marxismo revolucionario y, en menor escala, lo que aún quedaba del populısmo progresista (populismo de izquierda, si cabe el término). La victoria, en todos los casos, fue del sector monopólico del gran capital.

b) Es verdad, asimismo, que desde entonces pasó a plantearse el problema de forjar un nuevo sentido del orden, modelar nuevos actores y construir una nueva subjetividad o cultura. Cosas que fueron ocurriendo de manera lenta y a la vez tortuosa, mas no en el vacio sino sobre la base de la nueva correlación de fuerzas creada tanto por el contundente triunfo de las burguesías a nivel local, cuanto por el contexto mundial a que ya nos referimos.

Para quienes no lo tengan presente, conviene recordar que en 1976, por ejemplo, casi no existía país alguno de América Latina libre de algún tipo de dictadura militar, con el agravante de que, incluso las dictaduras en cierto sentido progresistas, como las de Perú, Ecuador y Honduras, habian virado ya a la derecha. Sólo a partir de 1977-78 las masas del continente comenzaron a recuperar la iniciativa, aunque en muchos casos (sobre todo en América del Sur) la capacidad popular de automovilización estuvo bastante por el encima del nivel 
orgánizo propiamente tal. Y es que sus anteriores organizaciones, cuadros y aparatos habían sido destrozados o reducidos a su mínima expresión, al mismo tiempo que su tradición (cultura política) fue cortada $o$ distorsionada por la verdadera contrarrevolución cultural que las dictaduras emprendieron con variable éxito. No olvidemos, por lo demás, que este período contrarrevolucionario coincide con el momento de un vertiginoso desarrollo de los mass media en Latinoamérica, que transforma con bastante profundidad nuestra cultura de masas.

En tales condiciones, el ritmo de las aperturas y negociaciones se anticipó casi siempre al ritmo de reorganización y de recomposición de la identidad política autónoma de las masas; lo cual no quiere decir, en modo alguno, que tales aperturas hayan sido ajenas a la presión popular. Pero si fue el celebrado momento (celebrado por quienes no querian ver a esas masas politizadas) de la espontaneidad: aquel lapso, finalmente breve, en que los "nuevos movimientos sociales" (TOURAINE, 1982, cap. VI), en el sentido tourainiano del término, parecían remplazar definitivamente a los "viejos" movimientos políticos. Situación que no tardo en revertirse, como el propio Touraine (1986, p. 12) lo reconoce 10 , mas sin que esto signifique que los movimientos populares hubiesen recuperado la totalidad del tiempo y la identidad perdidos. La burguesía, en cambio, aparecía remozada en el mejor estilo socialdemócrata, reorganizada y con un gran poder de convocatoria, como se nos enseñó a decir (antes llamábamos a eso poder de manipulación). Cosa poco común en América Latina, esa burguesía incluso apareció revestida de hegemonia (en la también flamante acepción del término), palpable a través de su capacidad de cooptación de muchos sectores hasta entonces rebeldes de nuestra intelectualidad.

Y es que en Aménca del Sur, sobre todo, esta intelectualidad había sido objeto de un doble tratamiento. De un lado, la más brutal represión: asesinatos, prisiones, tortura, exilıo, desmantelamiento de aquellos núcleos culturales (sobre todo universitarios) donde se producía una ideología anticapitalista y antimperialista De otra parte (lado carrot de la historia), un gran apoyo financiero que las principales fundaciones capitalistas dieron para la creación de institutos privados de investigación que con el tiempo vendrían a remplazar, en la producción y difusión de las ciencias sociales, a aquellas instancias víctımas de la represión. Nacía así esa extensa red de los que luego se autocalıficarian de centros de excelencia, torres de marfil libres incluso del bullicio estudiantil, y que no tardarían en generar e institucionalizar una enorme burocracia académica continental encargada, entre otras cosas, de obliterar todos los conductos de un pensamiento crítico que hasta entonces había sido la característica más relevante de la intelectualidad latinoamericana (crítico de las estructuras vigentes, claro está).

\section{¿Fin del "Fundamentalismo"? \\ En efecto, y contrariamente a lo que a veces se piensa, la vía prusiana 0 junker no genera en los países}

10 "En 1985, os atores poltticos dominan claramente sobre os atores sociais" en "As possibilidades da democracia na América Latina" (1986). 
dependientes una intelectualidad sumisa y conformista. Al contrario - y el ejemplo de América Latina lo atestigua - tal vía tiende a engendrar, como reacción contra ella, fuertes corrientes jacobinas, tercermundistas, leninistas. A menudo el propio marxismo no es (o por lo menos no fue) sino la culmınación de tales corrientes: noventa por ciento de los latinoamencanos de izquierda seguramente fuimos primero jacobınos $\mathrm{y}$ tercermundistas, luego leninistas (a veces avant la lettre) y sólo al final, y no siempre, marxistas. Todo ello, mezclado a dosis mayores o menores de populismo, fenómeno al que luego nos referıremos con más detenimiento.

Ahora bien, s1 algo ha impedido que el marxismo se socialdemocratice fácilmente en América Latina, es justamente la existencia de aquellos ingredientes que, por asi decirlo, han constituido la sal de la tierra de los movimientos revolucionarios contemporáneos y, desde la otra orilla, el principal dolor de cabeza de nuestros teóricos europeizantes 11 . Es natural, entonces, que el proceso de socialdemocratızación de América Latına, y por ende del marxismo de la región o de lo quede de él, pase por un empeño de erradicación de aquellas raíces. $i$ De qué manera viene esto ocurriendo?

En primer lugar mediante la invención de un pasado mítico, aunque reciente, en el cual los héroes de ayer son convertidos en los villanos de hoy. Gracias a este trastrocamiento de papeles, la izquierda marxista aparece como la principal culpable de los golpes de Estado ocurridos en las décadas de los 60 y los 70 , por más que en muchos casos sea incluso cronológicamente evidente que sus acciones armadas fueron una respuesta al golpismo burgués y, por lo mismo, no constituyeron una provocación sino más bien un acto de resistencia legítima contra la militarización de los Estados latinoamericanos. En el caso brasileño, por ejemplo, Weffort es enfático en señalar que:

\section{"Aunque las simpatias por la} revolución cubana vengan desde sus inicios, en 1959, las acciones armadas de la izquierda (brasileña, A.C.) sólo empezaron nueve años después, en 1968. Su preparación es posterior al Decreto Institucional No 2, de 1965, que disuelve los partidos politicos de la democracia de 1946 (. . .) Pretendo decir que, cualquiera haya sido su retórica, la lucha armada de aquellos años tenia el sentido de una lucha de resistencia. $Y$ se dio no porque en Cuba hubiese un régimen socialista, sino porque habia en el Brasil un régimen militar." (WEFFORT, 1986, p. 81.)

Y el mismo autor, que está lejos de abrigar simpatías por el Partido Comunista de su país, reconoce que:

"En todo caso es un hecho que, siempre que las circunstancias politicas les permitieron, los comunistas trataron de ceñirse a las reglas del juego democrático. Esto ocurrió especialmente después de 1954, lo cual les aseguró una posición

11 Como escribió alguna vez Torcuato di Tella: "El problema, para quienes profesan valores más universalistas, es cbmo adaptarse a las ásperas realidades del populismo". En la "tanda de partidos populistas" que enumera di Tella están incluidos, desde luego, los partidos de Lenin, Mao y Fidel Castro Cf. Gino Germani, Torcuato S. di Tella y Octavio Ianni en: "Populismo y contradicciones de clase en Latinoamérica" (1973), esp. p. 70, 71 y 82 . 
de activa participación en defensa de la legalidad democrática en 1961. También es cierto que después de 1964 buscaron siempre caminos democráticos para oponerse al régimen militar." (Idem, p. 79.)

Pero hechos como estos, que para los hombres honestos de la generación de Weffort constituyen una evidencia, no necesariamente lo son para los jovenes de hoy, mal informados con respecto a lo que de veras sucedio, pero saturados por las imágenes de la leyenda negra sobre el marxismo y los marxistas de los años 60 y 70: terroristas, fundamentalistas, golpistas de izquierda, ideologistas, atrasados, antidemocráticos. . . Adjetivos que hasta se llegan a aplicar a la experiencia de la Unidad Popular chilena, en tuna suerte de trágica ironía, pues, si de algo pecó aquella via, fue exactamente de un exceso de confianza, no en la democracia a secas, pero sí en la democracia burguesa que existía en Chile.

Ideolbgicamente cercado, sometido a cuarentena, el marxismo revolucionario viene sufriendo, simultáneamente, un proceso de estrangulamiento teórico que comenzó con una primera operación quirúrgica: la extirpación del leninismo. Si en Europa Occidental esta operación sirvió para limpiar al marxismo hasta de las más leves aristas revolucionarias (recuerdos jacobinos inclusive), entre nosotros se la viene usando, además, para resquebrajar nuestra conciencia tercermundista. No es una casualidad que el pensamiento conservador, desde Vargas Llosa hasta E. Krauze, insista en que la europeización de la izquierda latinoamericana es poco menos que un requisito del proceso civilizatorio:
"Entre los intelectuales europeos de izquierda ha tenido lugar un saludable replanteamiento, pero en América Latina la mayoria baila ain obedeciendo a reflejos condicionados como el perro de Pavlov." (BENEDETTI e VARGAS LLOSA, 1984, p. 48, nota 14.)

"(Es necesario) una izquierda que evolucione hacia formas europeas españolas - de acción y pensamiento." (KRAUZE, 1986.)

¿Civilización vs. barbarie? La vieja antinomia de Sarmiento ciertamente no es ajena a este tipo de reflexión. Pero la arremetida contra el marxismo revolucionario no proviene sólo del conservadurismo strictu sensu. Si hacia mediados de la década de los 70 la teoría de la dependencia, por ejemplo, era criticada desde su flanco izquierdo, en nombre de la teoría del imperialismo, un quinquenio más tarde las críticas eran ya abiertamente socialdemócratas o eurocomunistas, en nombre de la "interdependencia" y de la perspectiva de los supuestos "paises capitalistas de desarrollo medio". Además, a esas alturas, el nacionalismo antimperialista de algunos sectores de la izquierda iba convirtiéndose, grotescamente, en puro y llano patrioterismo. Con bastante retraso acababan de descubrir i la "cuestión nacional"!

El resto del proceso teórico es más conocido. Empezó con críticas y "autocriticas" a desviaciones del marxismo tales como el "economicismo" o el "reduccionismo clasista"1 2 ; críticas que hubieran tenido toda razón de ser si en verdad hubieran sido lo que aparentaban $y$ no lo que en verdad fueron: un pretexto para arrojar el agua sucia de

12 Cf. p. e. el trabajo ya clásico de Ernesto Laclau: “Polltica e ideologia en la teoria marxista" (1978). 
la bañera con niño y todo. En la crítica al "economicismo" se fue tan lejos, que hasta las más palmarias deficıencias de Gramsci en el análisis económico fueron rescatadas a título de "error fecundo" (COUTINHO, 1984, p. 72); a la vez que las clases se volatilizaban en favor de los "movimientos sociales". El concepto de "lucha de clases", que ya empezaba a parecer de mal gusto, fue remplazado por la oposición "Estado/sociedad civil", mientras el propio proceso de domınación política pasó a ser analızado en términos de simple "hegemonia". La explicación estructural era, a su turno, remplazadas por los análisis culturalistas, de un nivel no siempre encomiable, helas!

De este modo, el problema estructural de América Latina que, nos guste o no, sigue radicando en su condición subdesarrollada y dependiente, quedó completamente preterido. Se convirtıó, en el mejor de los casos, en un asunto técnico de competencia de los economistas. Desesperada ante la ramplonería y falta de vuelo de los cientistas que ella misma habia contribuido a crear, la propia burguesía latinoamencana acabó por que jarse - por boca del canciller

De este modo, el problema estructural de América Latina que, nos guste o no, sigue radicando en su condicion

subdesarrollada y dependiente, qued6 completamente preterido. Se convirtio, en el mejor de los casos, en un asunto técnico de competencia de los economistas. argentino Caputto por ejemplo - de la falta de economistas de la talla de un Prebisch o alguien parecido. E, ironía del destıno, tuvo que ser Alain Touraine el encargado de recordar a sus discipulos criollos que sería bueno volver a vincular lo social con lo político:

"El proceso democrático viene desarrollandose en muchos paises sin referencia a los problemas sociales más urgentes. Resultado de lo cual, las expectativas depositadas en los gobiernos democráticos se ven frustradas, lo que restituye mucha fuerza a los movimientos de tipo populista, a una politica de masas que es peligrosa para la democracia (...) El éxito de partidos de izquierda como el PDT de Leonel Brizola, el nuevo partido socialista de Miguel Arraes, en Recife, o el PT, indica la necesidad de una revinculación entre demandas sociales e instituciones politicas."

(TOURAINE, 1982, p. 12.)

Esta revinculación se produjo, en el caso brasileño, a través del Plan Cruzado, hecho que permitió la aplastante victoria del PMDB en noviembre de 1986. Alegría de pobre, como después se vio. El temor de que el PMDB se convirtiera en el $P R I$ brasileño no tardó en desvanecerse ante el fantasma redivivo de Leonel Brizola, a medida que la crisis volvía a mostrar sus raíces estructurales, más allá de los movimientos inerciales que los padres del Cruzado habian tratado de refrenar.

\section{El Fantasma (no exorcizado) del Populismo}

Para quen no es brasileño resulta una situación paradójica, no exenta de sarcasmo, ver a un país de 140 millones de habitantes, que además gusta ufanarse de su modernidad asi como de ser la octava potencia económica del mundo, marcando su compás político y alterando sus pulsaciones vitales en función de los gestos de un personaje al que los marginados perciben como una suerte de Llanero Solitario, mientras el oficialismo lo cataloga como un "caudillo bárbaro", portador del "caos y la irresponsabilidad". Brizola, a quien obviamente nos referimos, curiosamente no encabeza ningún movimiento armado ni pregona la 
revolución, no represente poder especial alguno que no sea el de su propio verbo $\mathrm{y}$, remate de la ironía, es un partner normalmente aceptado por la comunidad socialdemócrata internacional. ¿ En que reside entonces su peligrosidad y en que eștriba su irresponsabilidad?

El problema que deseo destacar a través del caso Brizola no es por supuesto inédito en América Latina y remite a un complejo juego de papeles y de máscaras, en el cual nunca es fácil establecer de qué lado se sitúa la supuesta bastardía y de cuál lado está la reivindicada legitimidad. ¿ Quién representa mejor al pars: aquellos políticos modernos que estudian sesudamente las formas en que ocurrieron los pactos político-sociales en los países de
Europa Occidental para aplicarlos en América Latina, o aquel caudillo que dice al pueblo que la socialdemocracia que él practica siempre habrá de conservar algo de esa "pimienta revolucionaria" que se necesita para construir el "socialismo moreno" en el Brasil?VI ¿Y quién está más cerca de la realidad: aquellos intelectuales ultrarrefinados que ya pregonan el fin de la escuela , o aquel lider populista que casi reduce su programa político a la multiplicación de construcciones escolares?

Para bien o para mal, la verdad es que el populismo siempre extrae su vitalidad de los estratos sumergidos de nuestro continente, de aquellas capas casi telúricas que el oficialismo, cuando no también cierta izquierda europeizante, se empecinan en

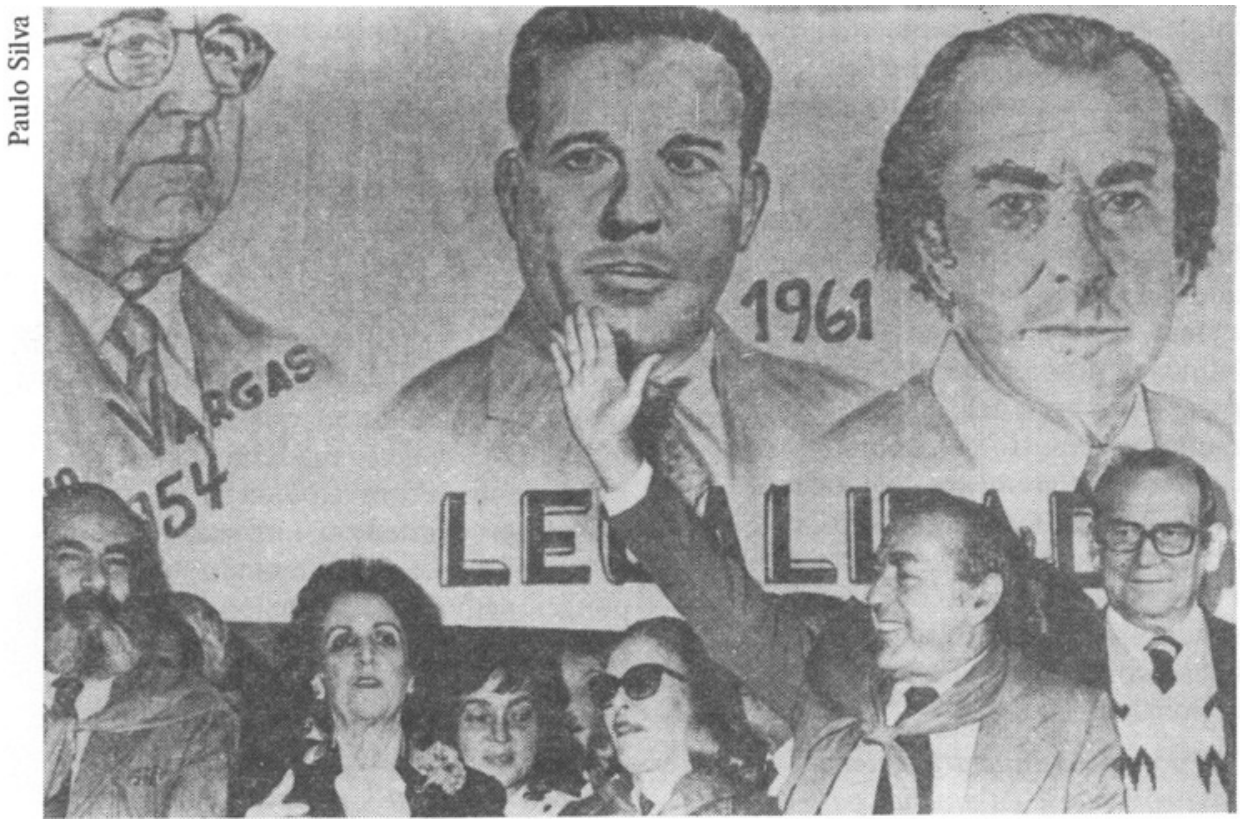

Comício brizolista, 1981

VI Frases empleadas por Leonel Brizola durante su participación en el programa "Roda viva", T. V. Cultura, Säo Paulo, 8 /junho/1987.
El problema que deseo destacar a través del caso Brizola no es por supuesto inédito en América Latina y remite a un complejo juego de papeles y de máscaras, en el cual nunca es fácil establecer de qué lado se situa la supuesta bastardra y de cual lado está la reivindicada legitimidad. 
desconocer. Como escribiera Martí hace casi un siglo.

'La incapacidad no está en el pais nactente, que pide formas que se le acomoden y grandeza úthl, sino en los que quieren regir pueblos originales, de composición singular y violenta, con leyes heredadas de cuatro siglos de práctica libre en los Estados Unidos, de diecinueve siglos de monarquia en Francia (...) El buen gobernante en América no es el que sabe cómo se gobierna el alemán o el francés, sino el que sabe con qué elementos está hecho su pais( . ) La forma de gobierno ha de avenirse a la constitución propia del pais." (MARTI, 1977, p 38-9)

El populısmo resurge, pues, en la estricta medida en que las transiciones democráticas (igual que las democracias fraudulentas del pasado) desvinculan intencionalmente lo social y económico de lo político o, lo que es peor, en la medida en que nuestras burguesías relacionan aquellos elementos de una manera históricamente perversa, que tiene más de chantaje que de pacto. En efecto, mientras en el convenio socialdemócrata clásico (europeo) las burguesías ofrecian ventajas materiales a las clases subalternas con el fin de consolidar la vida democrática de sus respectivas naciones, en nuestros países, las burguesías en lugar de pagar, cobran: bajo la amenaza constante de volver a dominar por medio del terror dictatonal, esperan que las masas populares escarmentadas renuncien a sus más elementales derechos económicos y sociales. Por eso, en el caso europeo no se temía hablar de una democracia social; en el nuestro, lo que se busca es una democracia absolutamente formal, sin adjetivos y sin condiciones. Así, todo pacto social se torna imposible (ahí están los ejemplos de Brasil, Uruguay, Argentina o Bolivia) y lo más que puede lograrse es un obligado pacto politico: una convergencia antidictatorial para ser más precisos.

En los años 60, el populismo fue criticado por sus insuficiencias, no por la savia popular que circulaba en sus venas Hoy, es vilıpendiado por la razón estrictamente inversa: porque con su retónica plebeya (jacobına a veces, tercermundista en otras) se encarga de recordarnos que no hemos dejado de ser pueblos pobres y colonuales, morenos o mestizos de Latınoamérica. Aguafiestas del proceso de occidentalización, el populismo de izquierda aparece además como un discurso irresponsable en la medida en que atenta contra la regla aúrea de la actual democratización de América Latına: pedır al trabajador que en lo económico (o sea en sus relvindicaciones salariales) se comporte como el nativo que en verdad es, pero que en lo político actúe como un auténtico cludadano escandinavo.

Por lo demás, cabe recordar que cuando ahora se habla de populismo, no siempre se está utilizando el término en la acepción latinoamericana tradicional. Muchas veces se lo emplea desde un punto de vista neoliberal, para condenar cualquier modalıdad de "welfare state"; en otras ocasiones, no pasa de ser un rótulo aplicado a diferentes formas culturales de las que se quiere abominar, como la literatura social de los años 30 o la poesía comprometida de la década del 60 . Se trata, en estos últımos ejemplos, de la mirada que la "posmodernidad" aséptica lanza sobre todo cuanto se aparte de un vanguardismo 
estrictamente formal (COUTINHO, 1984, p. 149)VII.

\section{¿Subdesarrollo de ayer, Modernidad de hoy?}

Otro dato que llama la atención de quien visita Brasil es la convicción generalizada de su modernidad. Dicha convicción se asienta, desde luego, en hechos tanto empíricos como ideológicos. Entre estos últimos, no es pequefío el residuo del discurso de "héroe modernizador" que adoptara el régimen surgido de la "revolución" (sic) de 1964, discurso que por lo demás empalmó admirablemente con la ideología del "gigantismo" que la clase dominante brasileña cultiv6 secularmente. Pero junto a la retórica tenemos también los hechos objetivos que nadie puede negar: durante el periodo 1965-84 el PNB per cápita brasileño se incrementó a un ritmo promedio anual del $4,6 \%$, sólo comparable, dentro de la 6rbita capitalista, con algunos de los milagros ocurridos en Asia o en ciertos países árabes. En este sentido, puede decirse que Brasil se comportó en dicho periodo más como un país "oriental" que "occidental".

Pero las razones de la fe en la modernidad no terminan ahí. Así como a un mexicano no le pasa por la cabeza la idea de insistir en la modernidad de su país por la sencilla razón de que el punto de comparación exterior es obligadamente Estados Unidos, a un brasileño le parece evidente su condición "moderna" en la medida en que el punto normal de referencia es Paraguay, Bolivia o Uruguay. $Y$ aún cuando se compara con la Argentina carece de razones para sentirse atrasado: en 1929 el nivel de vida de los argentinos era 5 y media veces superior al de los brasileños; hoy se encuentran prácticamente a la par (SINGER, 1978, p. 1-10). ¿Qué mejor prueba de modernización?

¿ Impresiones populares solamente, $y$ opiniones detectables también en el discurso teórico, incluso de la izquierda? El texto siguiente, de Carlos Nelson Coutinho, ilustra bien una idea compartida por buena parte de la intelectualidad brasileffa (no toda, por cierto):

"... el régimen posterior al 64 modernizó definitivamente el pais: $y$ modernizar, aunque sea de un modo conservador, significa desarrollar las bases objetivas sobre las que se asienta la posibilidad de construir una sociedad civil efectivamente autónoma. En esto radica, a mi parecer, la contradiccion fundamental de los regimenes autoritarios modernizadores pero no fascistas: tal como el aprendiz de brujo, desencadenan procesos que dificilmente son capaces de controlar después." (SINGER, 1978, p. 199.)

Más adelante me detendré a examinar hasta qué punto es verdad aquella historia de los militares-aprendices de brujo. Por ahora, me limito a sefialar que la observación de Coutinho sobre la modernización del Brasil parece tan empíricamente incuestionable cuanto teóricamente engañosa. En efecto, ique mismo significa modernizar definitivamente un país como Brasil? Obviamente, Coutinho no quiere decir con ello que Brasil alcanzó ya el pináculo del

VII Por esto, no deja de llamar la atención que Coutinho condene como "populistas" el realismo social de Jorge Amado o la poesía comprometida de Thiago de Mello. 
progreso - sería absurdo suponerlo ni afirmar que es la primera vez que ese pais experimenta un proceso de modernización - lo que equivaldría a desconocer la historia. $Y$ tampoco tengo la impresión de que el autor desee significar que los militares modernizaron a tal punto el Estado burgués, que tornaron irreversible el carácter capitalista del Brasil. Puede ser que esto último haya en verdad ocurnido y que la modernidad política de los paises más grandes de América Latina consista finalmente en ello. Sın embargo, la reflexión de Coutinho no parece encaminarse en tal dirección, puesto que apunta más hacia la sociedad civil que hacia el Estado.¿Se querrá decir, entonces, que algunas sociedades como la brasileña han dejado definitivamente de ser subdesarrolladas?

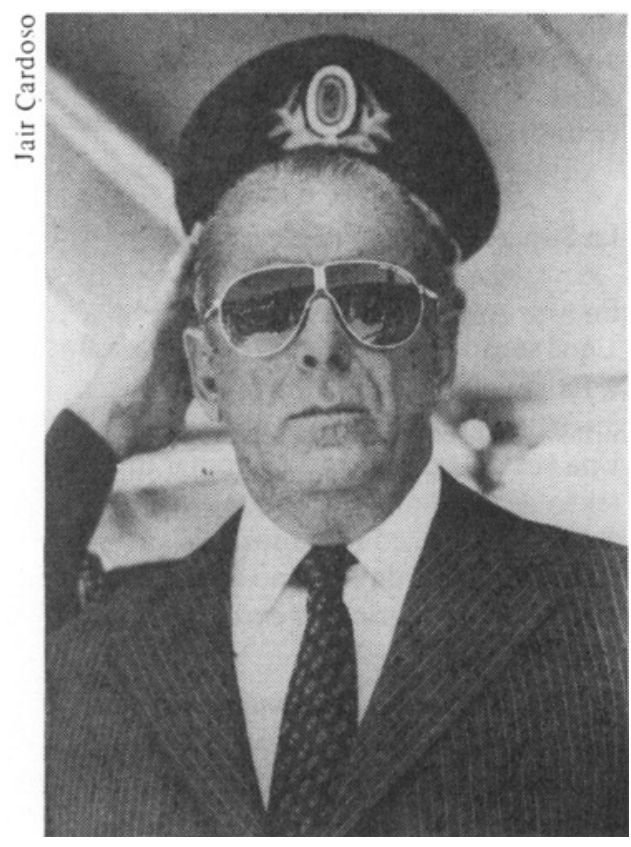

General João Batısta F'1gucuredo, 1981
No quiero enfrascarme aquí en una discusión interminable sobre lo que es o no es el subdesarrollo; pero sí voy a permitirme recordar algunos datos significativos que, sin cuestionar en lo más minimo el grado de modernización del Estado burgués en el Brasil, ponen en cambio en duda la supuesta robustez de la "sociedad civil". En 1981, o sea antes de que estallara la últıma crisis regional, Brasil ocupaba, en términos de PNB per cápita, el quinto lugar entre los siete paises más grandes de América Latina. Lo antecedían, en este orden, Venezuela, Chile, México y Argentina. El PNB per cápita brasileño era apenas superior a la media latinoamericana (2.048 dólares para América Latina y 2.347 dólares para Brasil), media que a su vez representaba menos de la cuarta parte de la media del "Primer Mundo" (10.721 dolares en ese mismo año) (FURTADO, 1986). Tres años después, en 1984, la situación no se había modificado mayormente: Brasil ocupaba el sexto lugar en América Latina por su ingreso per cápita (atrás de Venezuela, Argentina, México, Uruguay y Panamá) y en el mundo se ubicaba, según el mismo criterio, en el lugar número cincuenta. Francia tuvo aquel año un ingreso per cápita cinco veces superior al de Brasil y los Estados Unidos ocho veces mayor VIII.

Y si nos detenemos a examinar algunos indices de desarrollo social, la modernidad de la sociedad civil brasileña tampoco se impone como una evidencia. En 1985, o sea después de realizado el milagro económico, la tasa de mortalıdad infantil es exactamente igual en Ecuador y Brasil (67 por 1.000 en los dos casos); la

\footnotetext{
VIII Según datos del Banco Mundial/Fundação Getúlio Vargas en Relat ório sobre o desenvolvimento mundial - 1986 (São Paulo).
} 
esperanza de vida es mayor en el país andino (65 años para Ecuador, 64 para Brasil); la tasa de alfabetización de adultos, tanto para hombres como para mujeres, es más alta en Ecuador que en Brasil (85\% de hombres y $80 \%$ de mujeres alfabetizados en Ecuador, frente a 79\% y $76 \%$, respectivamente, en Brasil), y hasta las más recientes tasas de escolarización (periodo 1982-84) masculina y femenina son superiores en Ecuador que en Brasil (UNICEF, 1987, p. 127). Conviene subrayar, por lo demás, que si se comparan estos indicadores de bienestar con los de Costa Rica o Cuba, el atraso ecuatoriano y brasileño en tales campos se torna más que evidente (UNICEF, loc. cit.).

Pero, más allá de estas diferencias, ¿qué cabe pensar del desarrollo latinoamericano en su conjunto? Todo depende de cómo y con quien queramos medirnos. Comparados con nuestro propio pasado, sin duda hemos avanzado mucho: el PIB per cápita de América Latina, por ejemplo, se duplic6 entre 1950 y 1975. En cambio, si nos cotejamos con la media mundial (digo bien mundial y no del Primer Mundo), nuestro desempeño fue bastante mediocre: el PIB per cápita de América Latina creció en aquel lapso por debajo de esa media mundial (FURTADO, 1986, p. 18). $Y$ nuestro gap con respecto al Primer Mundo desafortunadamente aumentó desde la posguerra para acá, según el mismo indicador del nivel de vida. Además de que en algunos campos, como los de la educación y la salud, los últimos diez años no han sido especialmente felices para América Latina. Alguien podría decir, haciendo de la miseria ironía, que el estancamiento en estos rubros revela lo bien que hemos superado el populismo y otros tipos de asistencialismo y paternalismo estatales. ..

Noes mi intención seguir echando a perder la fiesta de la modernidad (que todavía no acabamos de pagar, por lo demás), aunque sí considero necesario llamar la atención sobre el hecho de que, a mi parecer, seguimos siendo países subdesarrollados. Lo cual quiere decir, por definición, que continuamos poseyendo una cara moderna y otra que ciertamente no lo es (la "Belindia" de la que hablan muchos intelectuales brasileños), en una relación simbiótica que les confiere unidad. Doble faz engañıfa que permite negar la existencia misma del progreso en nuestros arrebatos de catastrofismo ultraizquierdista (de los que la obra de André Gunder Frank sería la mejor expresión), o ver sólo "modernidad" y "modernización" por doquier, en momentos conservadores como los que vivimos hoy.

\section{La Superexplotación "Revisitada"}

En este contex to cabe preguntarse ¿ qué sucede con las clases trabajadoras? $i$ Existe o no existe la otrora tan discutida sobre o superexplotacion? Una vez más me gustaría retomar un texto de Coutinho, en el que este autor polemiza con algunos planteamientos de Rogério Freitas y Ruy Mauro Marini. In extenso dice así:

"Al desarrollar necesariamente las
fuerzas productivas, la productividad
del trabajo social, el capitalismo
prepara los presupuestos para que el
aumento de la tasa de plusvalia pueda
darse a través del crecimiento de la
productividad, y no de la
superexplotación. En este sentido,

No es mi intención seguir echando a perder la fiesta de la modernidad (que todavia no acabamos de pagar, por lo demás), aunque sí considero necesario llamar la atención sobre el hecho de que, a mi parecer, seguimos siendo parses subdesarrollados. Lo cual quiere decir, por definición, que continuamos poseyendo una cara moderna y otra que ciertamente no lo es (la "Belindia" de la que hablan muchos intelectuales brasileños), en una relacion simbiótica que les confiere unidad. 
ningǘn capitalismo - ni siquiera

el brasileño - conduce

necesariamente, en todas sus

etapas, a una pauperización absoluta

de las clases trabajadoras y del

conjunto de la población, tal como

Freitas parece suponer. Con el

aumento de la productividad del

trabajo se vuelve siempre posible -

dependiendo ciertamente del nivel

de la lucha de clases - combinar un

aumento de la tasa de ganancia con

un aumento del salario real de las

clases trabajadoras 0 , más

generalmente, combinar una

elevación de la tasa de acumulación

monopolista con una mejor

distribución de la renta entre los

sectores monopolistas y no

monopolistas. A menos que

aceptemos las tesis catastrofistas

y neoluxemburguistas de sectores

de la ultraizquierda, que afirman el

carácter estructural (y no sólo coyuntural) de la superexplotación

de la fuerza de trabajo en el capitalismo dependiente, el cual

tenderia necesariamente al

estancamiento (por causa de

una limitación permanente de los

mercados), tenemos que admitir que

también el capitalismo

dependiente-asociado promueve un

aumento de las fuerzas productivas

del trabajo social y, como tal, a

partir de cierto punto, puede

satisfacer las demandas de aumento

salarial y de mejor distribución de

la renta entre sectores monopolistas y no monopolistas. "(COUTINHO, 1984, p. 189.90.)

Para ir por partes, empecemos por señalar nuestro acuerdo con Coutinho en el sentido de descartar la pertinencia de las tesis estagnacionistas, con la necesaria aclaración de que el padre de ellas no es precisamente Marini (que en rigor ni siquiera las sostuvo en el tex to que Coutinho (1984) cita en su nota de pie de página - nota 29 , p. 190 -), siendo que más bien se trata, como Weffort lo hace notar, de tesis elaboradas por "figuras tan importantes del pensamiento económico brasileño como un Celso Furtado, con su 'teoria del estancamiento' de la economia brasileña"(WEFFORT, 1986, p. 82).

Central o periférico, autónomo o dependiente, el capitalismo tiene, sin duda, un mecanismo inherente de reproducción ampliada que determina, entre otras cosas, el desarrollo más o menos continuado de las fuerzas productivas. Hasta aqui estamos de acuerdo con Coutinho. Luego, es igualmente verdad que, en el plano de la abstracción más elevada, resulta prácticamente imposible sustentar una teoría de la sobrexplotación. Son varios cientos, si es que no miles de páginas (entre ellas algunas nuestras), las que ya han sido escritas para demostrar las inconsistencias teoricas de conceptos tales como págo permanente cie la fuerza de trabajo por debajo de su valor, prolongación permanente de la jornada de trabajo, etc. Sólo que, el hecho de que algo no aparezca con nitidez en el plano teórico no demuestra que no exista en el plano histórico; al igual que la dependencia, la superexplotación puede darse dentro de una constelación histórico-concreta sin que necesariamente refleje una legalidad teórica inexorable.

Al momento de redactar estas líneas, casi veinte años después de escrito el famoso texto de Marini, Dialéctica de la dependencia, tengo ante mis ojos la siguiente noticia periodística, que por cierto no proviene de ningún sector de la ultraizquierda: 
"Los intereses del Japón para invertir en México se están volviendo cada vez mayores, según afïrma la revista inglesa The economist. Además de que este pais podria convertirse en un gran abastecedor de petróleo para los japoneses, también es considerado como una importante plataforma de exportación, que facilitaria el acceso de Japón al mercado de Estados Unidos. El salario minimo mexicano diario, debido al bajo valor del peso, es de cerca de US $\$ 3$, equivalente a 420 yenes. $A$ ese precio, dice un banquero japonés a la revista norteamericana Business week, el trabajo es prácticamente gratuito." (Folha de S. Paulo, 1987, p. A-11.)

¿"Trabajo prácticamente gratuito" = superexplotación? Teóricamente la equiparación puede siempre discutirse, más ninguna controversia teórica podrá echar tierra sobre la miseria real. En efecto, si el salario mínimo mexicano ha llegado a tales niveles de pauperismo, el de Brasil es todavia peor: menos de un dólar y medio por dia en la segunda quincena de junio de 1987. Como comenta el mismo diario en otra de sus notas:

". . Brasil posee uno de los salarios minimos más bajos del mundo. Luego del reajuste de $20 \%$, el salario minimo pasa a valer apenas US $\$ 42,24$ (por mes, A.C.), mientras en Argentina llega a US\$140, en el Ecuador a US $\$ 104$, en Colombia a US\$84, en Uruguay a US\$74 y en el Peri a US\$ 53." (Folha de S. Paulo, 1987.)

iNos encontramos ante un problema estructural o frente a una cuestión meramente coyuntural? Digamos que, para ser una coyuntura, es demasiado prolongada. Me parece que se trata de un hecho por lo menos tendencial, dadas no tanto las características teóricas (leyes) del modo de producción capilalista, 0 del capitalismo monopolista de Estado, sino más bien las modalidades concretas de articulación del capitalismo en escala mundial, esto es, del imperialismo. En este sentido, creo que si algún error podemos detectar en el mencionado texto de Marini a dos décadas de distancia, ese error no radicaría en lo de la superexplotación sino en lo que dice respecto al subimperialismo: es éste el que jamás se concretizó, por razones que no es del caso entrar a discutir aquí. Brasil, México y la Argentina los tres candidatos a la categoría de paises subimperialistas permanecieron, por ello, en un lugar bastante menos airoso de lo que las tesis de Ruy Mauro dejaban entrever.

¿ Y el futuro? Por supuesto que nada está escrito fatalmente de antemano, aunque tampoco hay que hacernos la ilusión de que nos encontramos ante una página en blanco. La tendencia a la superexplotación (me parece, hasta que alguien demuestre razonablemente lo contrario) está en la agenda de nuestras relaciones con los países imperialistas por la sencilla razón de que sin superexplotación no hay la más remota posibilidad de pagar la deuda externa de América Latina (que actualmente bordea los $400 \mathrm{mil}$ millones de dólares). Cosa sabida por tirios y troyanos, desde el FMI que no en vano postula la más rigurosa austeridad, hasta los sindicatos del subcontinente que no por casualidad son unánimes en oponerse al pago de esa deuda.

Queda la incognita referente al poder de la lucha de clases, esto es, a su eventual capacidad de revertir esta y otras tendencias. En principio, 
nada impide que tal reversión ocurra; sin embargo, no me parece haber signos convincentes de que, por los menos en los países más grandes de America Latina, aquella lucha esté en una etapa ascendente.

\section{El Autoritarismo como Tendencia}

La discusión de temas como la modernidad o la superexplotación no se agota obviamente en sí misma, sino que tiene que ver con el análisis de nuestras perspectivas políticas. Afirmar que por fin estamos viviendo en sociedades modernas, en las cuales el sistema no necesitará más recurrir a la superexplotación, es, para muchos autores, una laudable manera de afirmar que ha llegado la hora de construir democracias sólidas y estables, con respeto pleno a los derechos de la persona humana y con justicia social. A la inversa, la expresión de dudas sobre nuestra modernidad (que algunos quisieran ver incluso como posmodernidad) y la denuncia de la persistencia de una superexplotación son interpretadas, a menudo, como un claro indicio de enemistad hacia la democracia.

Sin embargo, personalmente no me acabo de convencer de que la mejor manera de servir a la democracia sea tomando nuestros wishful thinkings por realidades, ni que, en sentido contrario, la búsqueda de la verdad, por triste que sea, pueda constituir un acto antidemocrático. i $\mathrm{O}$ es que de veras se piensa que la democracia latinoamericana sólo puede asentarse en un espacio plagado de lagunas mentales, verdades a medias y ambigiedades bien calculadas?

En este orden de ideas, la primera cuestion que no podemos soslayar es la de que las estructuras capitalistas subdesarrolladas engendran un autoritarismo tendencial históricamente comprobable (digo bien tendencial y no fatal). Para el caso de Brasil, por ejemplo, Francisco

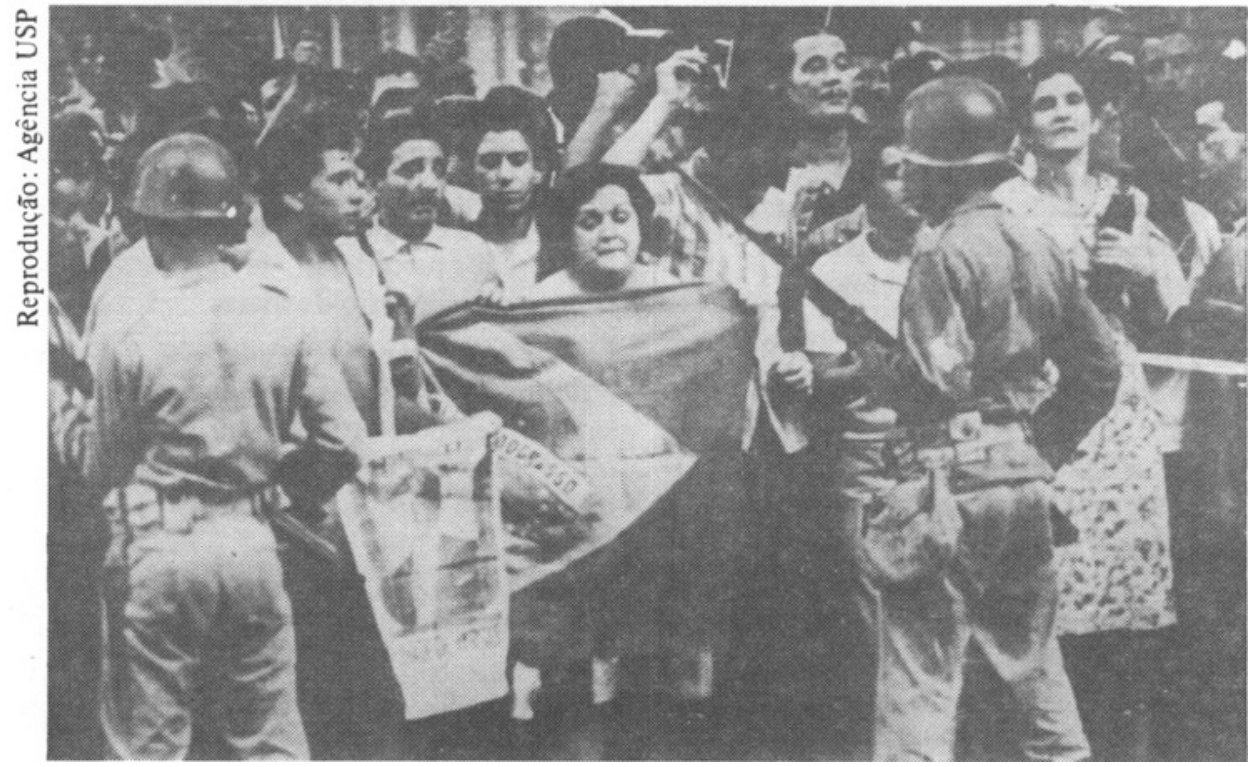

Manıfestação no Rıo de Janeiro contra o golpe militar de 1964 
Weffort observa lo siguiente, con mucha razón:

"La verdad es que en 160 años de historia independiente, Brasil no tuvo la oportunidad de corroborar la tesis de que la democracia es la forma por excelencia de la dominación burguesa. Si Marx hubiese sido brasileño, con seguridad habria dicho que la dictadura es la forma por excelencia de la dominación burguesa. $Y$ tal vez hubiera dicho también que la democracia es la forma por excelencia de la rebeldia popular."(WEFFORT, 1986, p. 67.)

A lo cual yo quisiera affadir que si Marx hubiese sido natural de cualquier otro país latinoamericano tampoco habría mudado substancialmente de opinión, y menos aún si le hubiese tocado nacer en Asia o Africa. Con su conocida ironía habría observado que Dios no reparte el maná de la democracia por igual entre sus hijos (para variar, a los blancos les ha tocado más que a los pueblos de color); y seguramente hubiera dicho que sólo un conocedor de los recursos más exquisitos de la retórica francesa, como Alain Rouquié ${ }^{13}$, podía emprender la tarea de demostrar, contra toda evidencia, que no existe correlación alguna entre la democracia, de una parte, $y$, de otra, el grado de desarrollo económico y el lugar que cada país ocupa en el seno de la cadena capitalista-imperialistaIX. Sin duda Marx habría anatemizado, igualmente, a quienes piensan que la cuestión democrática es antes que nada un problema cultural. Mosaico compuesto por mil culturas distintas y un generalizado autoritarismo, el mundo subdesarrollado y dependiente muestra cómo, más allá de esa abigarrada configuración cultural, ciertas tendencias estructurales persisten a lo largo de una tormentosa historia, hasta que las luchas populares de liberación consigan alterar conscientemente esos cauces antidemocráticos.

En este sentido, mal podemos olvidar que las últimas dictaduras sufridas por América Latina (igual o más que las anteriores) no son fruto del azar ni acontecimientos desconectados de las estructuras y los procesos de la llamada "sociedad civil". El golpe de Estado de 1964 en Brasil, por ejemplo:

“. . fue preparado con el apoyo de un amplio movimiento de opinión pública, del cual participó la mayoria de la clase media, de la burguesia y de la Iglesia, asi como toda la gran prensa y una buena parte de los partidos de centro y de derecha."(WEFFORT, 1986, p. 70.)

No fue pues un golpe de mano que el aparato represivo del Estado daba sobre el conjunto de una inocente sociedad civil. Y ni qué decir de un golpe como el de Chile, precedido, como todos recordarán, de un intenso trabajo reaccionario de masas.

Por tal razón, me parece además errado ver en aquellas dictaduras la simple presencia de una "fuerza bruta", carente de un proyecto histórico de clase. En este punto,

13 Cf. "O mistério democrático - das condições da democracia às democracias sem condiçōes", en Alain Rouquié y otros: Como renascem as democracias (1985)

IX Uno de los ejemplos esgrimidos por Rouquié para demostrar cbmo las democracias pueden florecer aún en las condiciones más adversas (gran pobreza, fuerte oligarquia, poca integración nacional, etc.), es el de Colombia; ejemplo que no se caracteriza por ser muy feliz. 
discrepo totalmente de opinıones como la siguiente, del mismo Weffort:

"Lo que llamábamos gobierno en aquellos años tenía mucho de parecido con una banda de gansters (. . .) Era un antigobierno, apenas más que una banda de sectarios que manejaba los instrumentos del poder en su propio beneficio y en beneficio de sus intereses privados, que tomaban al Estado como cosa suya. Los individuos que se decian gobierno trataban a la sociedad en general como un ejército de ocupación trataria a un pais ocupado. Si lograban dar la ilusión de constituir un gobierno era porque estábamos en pleno 'milagro económico', resultado de una coyuntura de expansión de la economia nacional e internacional a la que la propaganda insistia en considerar como una realización del poder."(WEFFORT, 1986, p. 67.)

Es cierto, desde luego, que las formas de dominación burguesa en los paises subdesarrollados poseen, por regla general, mucho de gansterl. Sin tratar de competir con los colores de mi pais en este triste terreno, diría que en el Ecuador actual, por ejemplo, el gobrerno civil y constitucional encabezado por León Febres Cordero tiene mucho de gansteril y otro tanto de lumpenesco. Sólo que, en muchos casos (que no parece ser el del gobıerno de Febres), lo gansteril no quita lo eficiente nı deja de ser una manera posible de gobernar. Bertold Brecht diría, por lo demás, que esto no es un patrimonio exclusivo de los países subdesarrollados.

Estımo, pues - con el perdón de Weffort y respetando su ira moralmente justa -, que en su momento la dictadura militar brasileña representó uno de los momentos más elevados de racionalización de los intereses burgueses monopólicos en América Latina, con una forma de gobierno suficientemente eficaz como para crear y desarrollar las condiciones óptimas de funcionamiento de cierta modalıdad de acumulación de capitalX. Esto no hizo desde luego la felicidad del pueblo, ni mucho menos; pero tampoco cabe esperar peras del olmo: fue un gobierno surgido de un movimiento contrarrevolucionario y provisto de un proyecto de clase perfectamente claro, como lo han demostrado hasta la saciedad estudios como los de un René Dreıfuss (1964), por ejemplo. En este sentido, incluso el que los militares tratasen al pueblo como un ejército de ocupación trataria a un pais ocupado, es un hecho execrable pero no necesariamente excepcional. De una parte, las oligarquías latinoamericanas siempre se consideraron verdaderas ocupantes de estos países de negros, indios, mestizos y mulatos (que no de ciudadanos ${ }^{14}$ ); de otra parte, la modernización de nuestros ejércitos fue realizada exactamente en la escuela de los ocupantes de Argelia y Vietnam. No aprendieron, pues,

X Una lectura del libro Geopolítica do Brasil, del general Golbery do Couto e Silva (José Olympio Ed., Rio de Janeiro, 1967), muestra, por lo demás, que los articuladores militares del "milagro" si tentan una visión de estadistas, por mucho que su linea politica se situie en las antipodas de nuestras propias convicciones.

14 Como dice José Munlo de Carvalho refinéndose a la Vieja República de principios de este siglo. "Na República que não era, a cıdade não tinha cidadãos" en Os bestializados O Rio de Janetro e a República que não foi (1987). 
a tratar a sus compatriotas como citoyens de París o como citizens newyorquinos, sino como a parias de la Casbah argelina o de las selvas de Indochina.

En esta óptica, y retomando una pregunta que dejamos pendiente, $i$ puede considerarse que las dictaduras latinoamericanas terminaron por representar el papel de aprendices de brujo o, más bien, estimar que realizaron exitosamente las metas que se habian propuesto?

Si partimos del supuesto de que los militares tomaron el poder por el mero capricho de gobernar indefinidamente, por cierto que la sola retirada a los cuarteles estaría confirmando su fracaso. Pero basta con recordar el pensamiento de un Golbery do Couto e SilvaXI, para el caso brasileño, o del civil Mariano Grondona, que tanto teorizo en favor de las dictaduras sudamericanasXII, para darse cuenta de que aquel supuesto es absurdo. Su proyecto consistía, en primer lugar, en acabar con el "peligro comunista", en segundo término en eliminar las veleidades "civil-populistas", en tercer lugar en "poner orden en el manejo de la cosa pública" $\mathrm{y}$, en cuarto término, en robustecer, incluso mediante el desarrollo economico, las "bases civiles de la democracia"; además de fortalecer y dar coherencia al Estado capitalista, claro está. La democracia que querfan cimentar era obviamente la de tipo burgués, que la década de los 70 tuvo, como se recordará, una sutil adjetivación: democracia viable.

¿ Fracasaron las dictaduras en algunos de estos objetivos? La brasileña prácticamente en nada, aunque hubiera preferido un país sin Brizola y sin el ala izquierda del PT. En el caso argentino, la dictadura obtuvo también algunos de los frutos esperados: la sociedad civil fue encaminada hacia la moderación, dentro de límites harto estrechos; la intelectualidad de izquierda sufrio un trauma tan profundo, que quedó vacunada en contra de cualquier actitud antisistema. A diferencia de sus colegas brasileños, los militares argentinos no poseen la aureola de grandes modernizadores; tienen, en cambio, una eficiencia represiva internacionalmente reconocida (su know how en la materia llegó a ser objeto de exportación). Los únicos que hasta ahora han fracasado en su objetivo final son los militares chilenos, en razón de la enorme consistencia orgánica de la izquierda; pero por eso mismo se mantienen tenazmente en el poder (les es prácticamente imposible encontrar una fórmula de democracia viable).

En rigor, ninguna de las dictaduras ha salido verdaderamente derrotada; ni siquiera la uruguaya que perdió un plebiscito y tiene que haberselas con una izquierda relativamente fuerte. Por eso, los juicios a los torturadores hasta ahora han fracasado

XI Teórico del golpe del 64, Golbery fue también, significativamente, el teórico de la apertura a finales de los 70 y comienzo de los 80 .

XII En los múltiples editoriales que publicó en la segunda mitad de la década de los 70 , en la revista Visión, Grondona insistió siempre en que las dictaduras onosureñas eran el equivalente historico de las monarquias absolutistas de Europa, cuya misión era sentar las bases de la futura democracia.

En rigor, ninguna de las dictaduras ha salido verdaderamente derrotada; ni siquiera la uruguayra que perdió un plebiscito y tiene que habérselas con una izquierda relativamente fuerte. Por eso, los juicios a los torturadores hasta ahora han fracasado tanto en Argentina como en Uruguay, y en Brasil ni siquiera han llegado a plantearse. 
tanto en Argentina como en Uruguay, $y$ en Brasil ni siquiera han llegado a plantearse. No hay que olvidar que los procesos de Nuremberg fueron posibles porque los nazis, además de cometer crímenes abominables, habian perdido la guerra. Lo otro, es tan iluso como esperar que Francia procesase a sus militares que cometieron crimenes contra la humanidad en Argelia, o que los encubridores estadounidenses de Barbie (que todo el mundo sabe quienes son) fuesen juzgados junto con su protegido. La historia ciertamente tiene su moral, y por supuesto su justicia, pero enmarcadas dentro de ciertas correlaciones de fuerzas.

En fin, me parece que aún no debemos hacernos mayores ilusiones sobre la profundidad de nuestros procesos democráticos. Las tendencias autoritarias siguen vigentes $y$, por el momento al menos, el reposo del guerrero dista mucho de ser completo. Vivimos lo que en términos de Adam Przeworski se denominarían regímenes de "democracia tutelar". Esto es:

“. . regimenes en los que las fuerzas armadas se separan del ejercicio directo del gobierno y se retiran para sus cuarteles, pero lo hacen ordenadamente y listas para cualquier eventualidad. A pesar de las elecciones $y$ de los representantes electos, en tales regimenes las fuerzas armadas continian rondando cual sombras amenazadoras, prontas para lanzarse sobre quienquiera que vaya demasiado lejos en la amenaza a sus valores o sus intereses. "(PRZEWORSKI, 1984, p. 36.)

$\mathrm{Y}$ lo peor, añadiría, es que ello no obedece a la sola imposición de las fuerzas armadas. Incapaces de articular una verdadera hegemonía, en la acepción gramsciana del término, son las propias burguesías latinoamericanas las que recurren, ora abierta, ora veladamente, a la amenaza de nuevas intervenciones militares. $O$ son ellas, también, las que inevitablemente terminan cediendo ante el menor amago golpista, porque en el fondo temen más a las masas movilizables que a los fascistas uniformados. Abril de 1987, en Argentina, fue una clara cuanto dolorosa ilustración de esta situación.

\section{La "Sociedad Civil": ambigüedades teóricas e ilusiones empíricas}

¿. El mundo occidental en general, y América Latina en particular, están viviendo realmente una era de renacimiento de la sociedad civil? No es fácil responder a esta pregunta en la medida en que ella nos sitúa en un típico espacio de ambiguedad en el que pueden rondar muchos espectros, desde el de la primera ministra inglesa Margaret Thatcher hasta el del pensador Antonio Gramsci, o al menos de lo que cierta posteridad ha hecho de él.

En efecto, desde el año 1979 en que asumió el cargo para el que acaba de ser relecta por segunda ocasión, la señora Thatcher no ha dejado de bregar teórica y prácticamente por la desestatización de la economía inglesa, o sea, por su privatización, yendo en este sentido tan lejos que hoy se habla de su "revolución conservadora" 15 . $i$ Triunfo de la sociedad civil sobre el Estado? Si se

15 A st la califica la revista Newsweek, p. e. Cf. "The amazing Mrs. T", June 22, 1987. 
quiere, sí. Los términos son tan elásticos que todo depende del contenido político que coloquemos detrás.

En el caso de América Latina la fortuna del concepto de sociedad civil obedece, sin embargo, a algo muy distinto del antiestatismo (económico) que orienta la política thatcheriana, reaganiana 0, lo que es igual, fondomonetarista. Entres nosotros, tomar el partido de la sociedad civil quiere decir, llanamente, oponerse a las dictaduras, rechazar el autoritarismo encarnado en lo militar. Sólo que, sobre la base de este rechazo legítimo a la exacerbación de la función de dominación por parte del Estado burgués latinoamericano, la onda conservadora de Occidente penetra para intentar llevar el agua a su molino, insistiendo en la total desestatización de nuestras economías $y$, a veces sobre todo, en el desmantelamiento de los últimos vestigios del Estado benefactor. Se apunta, de este modo, al máximo recorte de los gastos sociales (educación, salud, vivienda popular) $y$ al fin definitivo de los subsidios: subsidio a los bienes de primera necesidad, se entiende, que no los

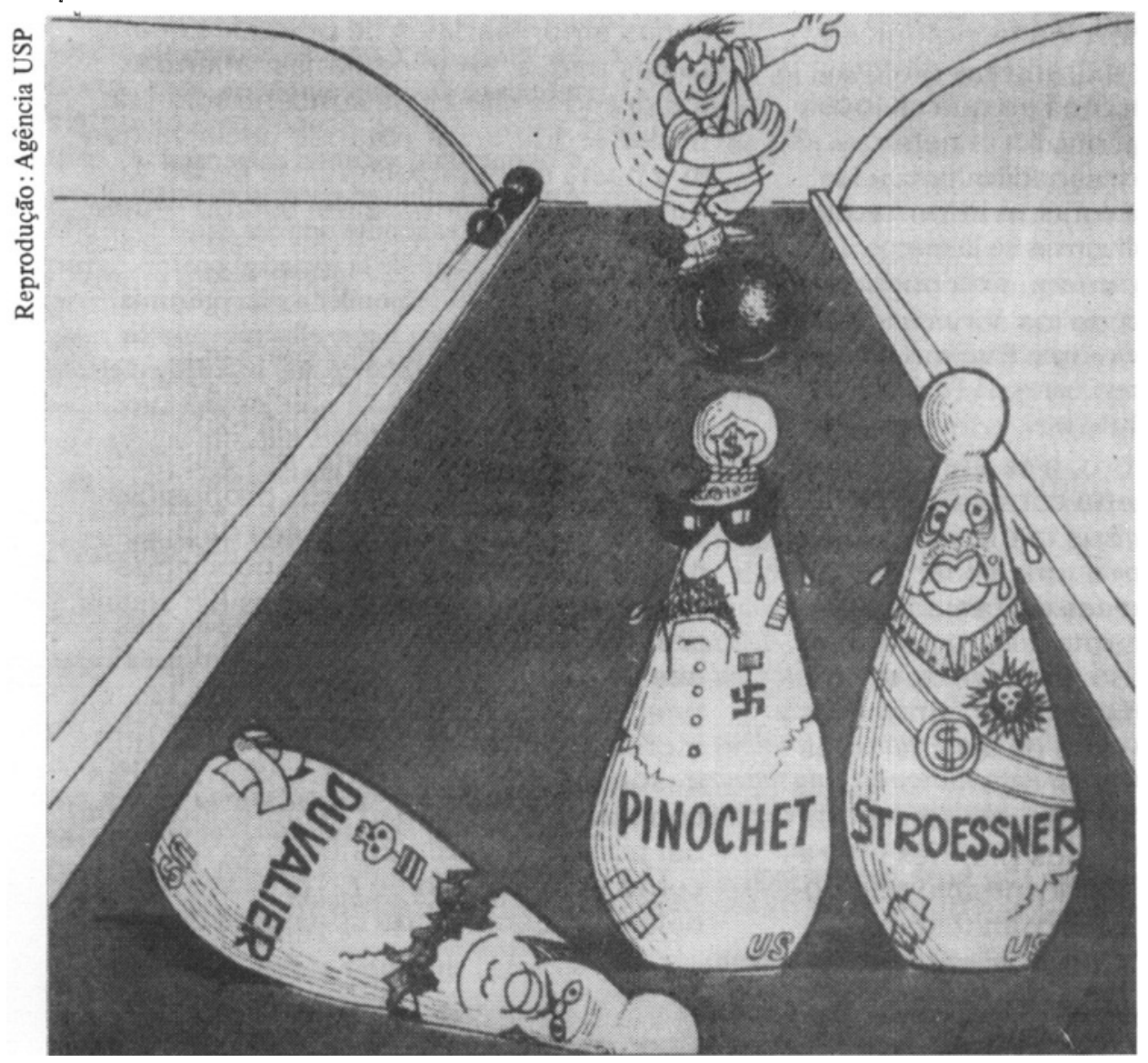


recibidos por el gran capital bajo el nombre de incentivos.

Como puede verse a través de estos ejemplos, la contraposición Estado/sociedad civil, lejos de ser un sustituto analítico de las contradicciones de clases, es un campo en el que se refleja la lucha de éstas, descubriendo y a la vez encubriendo los divergentes proyectos historicos.

Empero, más acá de la dimensión propiamente política existe también un problema teórico (y aquí entramos en el ámbito gramsciano) en el que la forma de relación Estado/sociedad civil pareciera ser la marca distintiva entre Occidente y Oriente, que nos llevaría, casi ineluctablemente, a cierta ecuación explicativa de lo civilizado-democrítico, de una parte, y lo primitivo-antidemocrático, de otra.

Sin entrar a discutir la legitimidad de un esquema que, para comenzar, ignora la relación historica entre esos dos polos (como si nada tuvieran que ver entre sí Occidente y Oriente), quisiera insistir en las limitaciones de la tan conocida y a la vez sibilina afirmación de Gramsci:

"En Oriente, el Estado era todo, la sociedad civil era primitiva y gelatinosa; en Occidente, entre Estado y sociedad civil existia una justa relación y bajo el temblor del Estado se evidenciaba una robusta estructura de la sociedad civil. El Estado era sólo una trinchera avanzada, detrás de la cual existia una robusta cadena de fortalezas y casamatas. .." (GRAMSCI, 1975, p. 95-6.)

Me limito aqur a plantear el siguiente problema: i qué quiso decir exactamente Gramsci con eso de "robusta estructura de la sociedad civil" ? ¿Quería advertir con ello que el orden burgués se había robustecido de tal forma, que ahora estaba presente en todos los intersticios del cuerpo social? Personalmente me inclino a pensar que es ésto, y no otra cosa, lo que Gramsci detect6, y que la historia le ha dado plena razon: hasta finales de 1987 , en que termino de redactar este texto, ninguna revolución ha ocurrido en Occidente ni se vislumbra el más leve movimiento en dirección al socialismo. Por el contrario, vivimos la época de las "revoluciones conservadoras" y de la estigmatización, incluso, de las pasadas revoluciones burguesas (de la francesa, por ejemplo).

Habida cuenta de esta evidencia difícil de soslayar, lo menos que cabe esperar de los análisis latinoamericanos inspirados en Gramsci, es que sean claros en cuanto a decir si les parece o no que la América Latina actual registra un grado tal de robustecimiento de la burguesía y del Estado burgues, que ha convertido al capitalismo en un hecho irreversible. Si es así, no me parece escandaloso aspirar a un capitalismo que al menos sea 10 más democrático posible en el plano político: una "via italiana", si se quiere. Lo que en cambio me parece iluso - para no usar un término más fuerte -, es concluir, por un lado, a la "occidentalización" definitiva de nuestras sociedades (o por lo menos de algunas de ellas) y, por el otro lado, celebrar las posibilidades, por fin materializadas, idel socialismo!

En rigor, hasta me atreverfa a decir que el concepto de "robustecimiento de la sociedad civil" ni siquiera puede ser interpretado como sinónimo de entrada en la "era de las grandes onganizaciones de masas", como 
algunos analistas dejan entrever.

Estados Unidos, ejemplo por antonomasia de tal "robustecimiento", está lejos de caracterizarse por dicho tipo de organizaciones. $E$ incluso Europa Occidental viene registrando, precisamente en esta década, el paulatino desvanecimiento de los organismos sindicales y hasta de muchos de los denominados "nuevos movimientos sociales", amén del reflujo de los partidos de izquierda.

¿ Es posible detectar fenómenos análogos en América Latina? La primera cuestión que me gustaría observar es que nuestra "sociedad civil" no ha sido necesariamente "primitiva y gelatinosa" en el pasado reciente. Hubo lugares y segmentos sociales que lo eran, otros que no. El Chile de la Unidad Popular, por ejemplo, parecía tener una sociedad civil harto desarrollada, tal como lo registró Régis Debray en este pasaje indeleble, que data de 1971:

"Más allá de sus alteraciones momentáneas - las ha tenido, pero breves -, la democracia liberal burguesa que ha marcado hasta hoy dia con su sello todo el tejido social chileno, ha demostrado una excepcional capacidad de amortiguamento, de recuperación y de conciliacibn. Ella ha proporcionado y continuia proporcionando la ideologia dominante, el legalismo y la juridicidad, que permanecen en el ambiente; las estructuras politicas de encauzamiento, es decir, un cuadro institucional estable; $y$ todo un sistema de representaciones vividas al nivel más prosaico, mitos de la Libertad y de la Ley con mayniscula difundidos hasta en los comportamientos de los explotados. No desaparecerá con un simple guiño, porque incluso si el Estado actual fuera derribado mañana, toda la 'sociedad civil' estí impregnada de ella. Chile, en este sentido, pertenece a esas sociedades 'occidentales' de las que hablaba Gramsci, en las cuales, detrís de la fortaleza principal del Estado, que puede siempre ser tomada por un golpe de mano afortunado, se escalona en profundidad toda una red de trincheras, de fortines $y$ de bastiones cuya conquista no puede ser tan simple."(DEBRAY, 1971, p.18-9.)

Además de ilustrar el tipo de lectura que los propios marxistas europeos hicieron de Gramsci muy a comienzos de los años 70, el texto revela bien el grado de consistencia ideológica, cultural $e$ institucional de la sociedad civil chilena de entonces. En dichos niveles, o sea, sudesarrollo $y$ dependencia a parte, Chile era obviamente occidental. Alain Touraine reconoce que incluso el movimiento obrero chileno, con su elevado grado de autonomía organizativa, parecía constituir uno de los puntales de la democracia tradicional chilena:

"La fuerza de la democracia chilena se basó (...) en la existencia de un movimiento obrero que sin duda tenia orientaciones politicas fuertes, pero que actuaba más como una fuente de legitimidad para los partidos de izquierda que como instrumento sindical de tal o cual partido."

(TOURAINE, 1982, p. 12.)

El problema de Chile no era, pues, el de una sociedad civil débil, primitiva y geltinosa, sino el de una bürgerliche Gesellschaft en la que el elemento "Bürger" no consiguio afirmar indiscutiblemente su "hegemonia" frente a las clases populares. $Y$ hasta 
hoy no lo consigue, i14 años después del golpe de Pinochet!

El caso de Uruguay guardaba bastante semejanza con el de Chile, aunque el espacio izquierdizado de la "sociedad civil" era menor. Incluso en el caso argentino no me atrevería a decir que la sociedad civil hubiese sido débil en las cuatro últimas décadas, sobre todo si del concepto de sociedad civil extraemos el elemento económico; era la hegemonía burguesa la que no lograba tomar forma, definirse más allá de la ambiguedad populista. $Y$ tampoco en Bolivia el problema podía plantearse como de una sociedad civil débil en general, sino, como también lo señalara Régis Debray, de un superproletariado enfrentado a una infraburguesia:

“. . hay en Bolivia un contraste acentuado entre los platillos de la balanza de clases (.. .) que opone, desde un punto de vista cualitativo, a un superproletariado una subburguesia que hace tan poco el peso, como se dice, que ella debe sin cesar restablecer el equilibrio por la fuerza represiva de las armas o bien ceder el lugar a este sucedáneo de burguesia moderna que constituye una burocracia militar, desgarrada entre vertiginosas veleidades reformistas y sus reflejos de miedo reaccionario frente al ascenso del poder sbrero" (DEBRAY, 1971, p. 18).

¿ Qué ha occurrido en estas y otras sociedades civiles similares de América del Sur? i Son ahora más fuertes o más débiles que hace 15620 años? En general puede decirse que aquellos segmentos de la sociedad civil en los que el pueblo tenía cierto grado de hegemonía se han debilitado (han sido debilitados por la represión, para ser más precisos), mientras que la hegemonía burguesa se ha ampliado relativamente. Verdad es que esa burguesía dista mucho de ser amada y reconocida por su capacidad de dirección espiritual y moral, mas en cambio ha logrado ser temida. Protegida por ese paraguas de temor (todo el mundo sabe ahora que tal burguesía es capaz de usar sin límites ni escrúpulos el peor terror cuando fuere menester), ella intenta, como es obvio, construir lo más rapidamente posible el mayor número de casamatas y fortificaciones ideológico-institucionales. El pueblo también, pero su libertad de movimientos es condicional, vigilado. Para eso están, incólumes, las fuerzas armadas.
¿ Puede, en tales condiciones, seguir profundizándose el proceso democrático? Si, pero probablemente por el lado burgués y conservador, sobre todo en los países
latinoamericanos considerados como de desarrollo capitalista medio. Como escribe Przeworski(1984, p. 46), "el conservadurismo social y económico puede ser el precio que haya que pagar por la democracia". Y para pactar ese precio siempre habrá, además, algún Santiago Carrillo dispuesto a explicar a los trabajadores que "es mejor ceder plusvalia a la burguesia que tener que habérselas con un destino todavia peor" (PRZEWORSKI, 1984, p. 43)XIII. Posibilidad que, por su lado, echa por tierra la retónca afirmación de que, a la larga, la democracia es incompatible con el capitalismo. Retórica, decimos, porque esa frase tan hueca como triunfalista no hace

XIII Citado por Przeworski y retraducido por mi. 
más que soslayar el problema de fondo; es decir, el tipo de democracia del que se está hablando. La democracia que se viene construyendo en Nicarágua, no lo dudo, puede ser en su perspectiva histórica incompatible con el capitalismo (es el único punto en que coincido con la opinión de R. Reagan). La democracia que se viene construyendo en Brasil o la Argentina no me parece, en cambio, apuntar hacia tal incompatibilidad. Problema general que, mutatis mutandi, no deja de recordarme aquellos tiempos en que algunos filósofos marxistas trataban de convencernos de que el arte en general es incompatible con el capitalismo, sin siquiera tomar conocimiento de los precios a los que se vendían los cuadros en el mercado de Nueva York....

\section{Nación, Transnacionalización y Democracia}

A juzgar por el tenor de ciertos textos, pareciera que los últimos afios de la historia latinoamericana se hubieran caracterizado por el renacimiento de la cuestión nacional, según algunos autores, o por la conformación de una voluntad nacional, según otros. Por mi parte debo confesar que, dejando de lado lá demagogia de ciertos discursos, oficiales o no, me resulta imposible ubicar con precisión aquellos lugares en que tal fenómeno supuestamente ocurre. En Sudamerica, por ejemplo, creo que el Perú es el único país en donde el nacionalismo parece mantenerse vivo y respirando todavia con algín brio, aunque ya se vislumbra el precio que la derecha local y el imperialismo están dispuestos a hacerle pagar por tal anacronismo. En los demás países, la invocación de la nación no pasa de ser el homenaje nostálgico que el vicio suele rendir de cuando en cuando a la virtud. Muchas veces me he preguntado, por ejemplo, si el mismo resurgimiento del indigenismo en determinados estratos de la sociedad ecuatoriana actual, es algo más que el último saludo a la autoctonía perdida, por parte de aquellas capas aborígenes en rápido proceso de aculturación (como antes se solía decir).

En Centroamérica habría que analizar el problema con mayor detenimiento, pues tenemos situaciones que van desde el nacionalismo revolucionario (antimperialista) de Nicarágua hasta el chauvinismo conservador de Costa Rica, pasando por las tribulaciones de lo nacional en Panamá. En cambio, en el norte, el nacionalismo mexicano atraviesa sin duda por una de sus peores crisis, sutilmente resumida en estas líneas de Roger Bartra:

"El nacionalismo mexicano ha llegado a un punto critico: no sólo resulta una odiosa fuente de legitimación del sistema de explotación dominante, que busca justificar las profundas desigualdades $e$ injusticias por medio de la uniformización de la cultura politica: ello comparte con todos los nacionalismos; pero además - y en ello radica la situación critica - las cadenas de transfiguraciones $y$ transposiciones han acabado por perfilar una cultura politica que ya no corresponde a las necesidades de expansión del propio sistema de explotación. Aún el avance de un capitalismo brioso e imperialista choca abiertamente con la estela de tristezas rurales, de barbaries domesticadas por caciques, de obrerismo alburero y cantinflesco, de ineficiencia y corrupción en nombre de una cohorte de pelados Pero no se trata solamente de una
A juzgar por el tenor de ciertos textos, pareciera que los áltimos años de la historia latinoamericana se hubieran caracterizado por el renacimiento de la cuestión nacional, según algunos autores, $o$ por la conformación de una voluntad nacional, segun otros. Por mi parte debo confesar que, dejando de lado la demagogia de ciertos discursos, oficiales o no, me resulta imposible ubicar con precisión aquellos lugares en que tal fenómeno supuestamente ocurre. 
necesidad del desarrollo económico por salir de la crisis y del estancamiento; una gran parte de los mexicanos comienza a rechazar esa vieja cultura politica que ha sido durante más de sesenta años la fiel compañera del autoritarismo, de la corrupción, de la ineficiencia y del atraso (. . .) Los mexicanos han sido expulsados de la cultura nacional; por eso, cada vez rinden menos culto a la metamorfosis frustrada por la melancolia, a un progreso castrado por el atraso (. . .) Han sido arrojados del paraiso originario, y también han sido expulsados del futuro. Han perdido su identidad, pero no lo deploran: su nuevo mundo es una manzana de discordancias $y$ contradicciones." (BARTRA, 1987, p. 241-2.)

Y los relojes caribeños tampoco parecen marcar la hora de lo nacional, con la probable excepción de Haití. En franco proceso de despolitización, para no decir de descomposición, aún el nacionalismo puertorriqueño, otrora símbolo de nuestras mejores aspiraciones independentistas, pareciera deslizarse - en los textos de algunos intelectuales al menos hacia una versión bastante folclorica de sí mismo.

Si uno analiza el proceso latinoamericano desde otros ángulos, también es fácil comprobar cuanto hemos caminado en el sentido de una desnacionalización. Como escribe André Furtado a propósito de la crisis latinoamericana actual:

"Hay una) pérdida de autonomia y de capacidad de decisión por parte de estas sociedades. Frente a una crisis tan profunda, las élites y las clases dirigentes parecen estar sin la minima capacidad de decisión autónoma, para engendrar una alternativa. En este punto, la situación actual se opone radicalmente a la de 1930, cuando hubo la formulación de una política industrializante frente a la crisis. El proceso de apertura de esas economias las llevó progresivamente a una desagregación de los centros de decisión nacionales. La propia situación de descontrol de los gobiernos en relación con la inflación ilustra bien este fenómeno. En este sentido, la lógica de la reciente crisis refuerza ese aspecto en la medida en que concentra el poder en la economia central. La intervención del FMI en la politica económica de numerosos paises latinoamericanos ilustra bien este punto." (FURTADO, 1986, p. 30.)

Junto con esta pérdida de autonomía y soberanía se da también un proceso de internacionalización de todas las esferas de la vida social, comenzando por la propiamente política. En efecto, si exceptuamos unos pocos partidos comunistas y afines que se especializan en marchar a contrapelo de la historia (eran internacionalistas cuando vivíamos la era de los nacionalismos y están tornándose ultranacionalistas cuando el mundo se transnacionaliza), el resto de partidos políticos se inscribe, por regla general, no sólo dentro de corrientes sin duda universales, sino también dentro de organizaciones internacionales como la socialdemócrata, la demócrata cristiana e incluso la de los liberales. Hecho sintomático, aún los viejos caudillos como Joaquín Balaguer, y no se diga los más jóvenes como Leonel Brizola, han tenido que rendirse ante este embate de la modernidad. Y yo, personalmente, no veo nada de censurable en ello: sólo destaco que es un fenómeno nuevo, prácticamente inexistente en la 
América Latina de hace 10620 afios, según el caso.

La intemacionalización de las pautas de consumo (de un consumo estratificado, claro está), con todo lo que ello significa en términos de transnacionalización de la cultura, asr como la tendencia a la relativa estandarización de los medios de comunicación de masas (que siempre conservan, desde luego, cierto aderezo local), tampoco parecen ser pruebas del más leve desplazamiento en favor de lo nacional. Incluso dicho aderezo es cada día menos original en la medida en que la industria latinoamericana de telenovelas, por ejemplo, tiene que recurrir a determinados ingredientes susceptibles de producir efectos lacrimógenos desde el Río Grande hasta la Patagonia, cosa que efectivamente ocurre con las producciones mexicanas, venezolanas o brasilefías. A su manera, estas novelas también hablan un lenguaje universal: el del $k i t s c h$.

En fin, deseo destacar otro fenómeno que me ha llamado áltimamente la atencion: la rapida transnacionalización de la alta cultura. No solo que vemos simultáneamente los mismos cult-movies (además de los otros) en los diferentes países de América Latina, sino que también leemos, concomitantemente y con independencia de los gustos nacionales, el mismo Mishima, el mismo Milan Kundera, el mismo Patrick Sïskind y la misma Marguerite Duras, que los grandes aparatos de producción y distribución cultural ponen a nuestra disposicion XIV. $O$ que nos imponen, eso habria que discutir.

Nada de lo anterior niega el hecho de que los espacios nacionales siguen existiendo; en la medida en que continúan habiendo Estados que articulan ciertos noveles de poder, ciertas modalidades concretas de acumulación de capital y cierta historia oficial, a partir de lo cual los sujetos históricos se constituyen y encuentran por lo menos una "comunidad ilusoria" (para retomar la olvidada expresión de Marx). Sólo que la logica de articulación de estas totalidades es cada vez menos local y más transnacjonal, y los centros de decisión última no residen, precisamente, en aquella mitica voluntad nacional.

\section{Democracia y Poder}

Y asf llegamos al momento de plantear uno de los temas más importantes - y curiosamente olvidados - del momento actual; a saber, la relación entre democracia y poder. En resumen, puede decirse que al respecto hay dos tesis:

a) La que sostiene que la democracia consiste en "la libertad de participación del conjunto de los ciudadanos, a través del voto, en los momentos de constitución del poder": en esta perspectiva, el poder nacería de las urnas.

b) La que concibe a la democracia no tanto como una manera de

XIV En Brasil, p. e., fue raro que en los años 1986 y 87 algín autor nacional lograse mantenerse consistentemente en las listas de best-sellers, tanto de ficción como de no ficción. Entre los pocos que lo consiguieron - si es que no fue el único - se encuentra Fernando de Moraes con su libro Olga, sabia mezcla de biografla, novela y - por qué no decirlo - melodrama. 
construir el poder, cuanto como una forma de relación del conjunto de ciudadanos con un poder estructuralmente determinado. En esta óptica, el poder no nace de las urnas sino de cierta configuración socio-estructural.

El problema de la primera concepción reside, a nuestro parecer, en su carácter absolutamente ilusorio, alejado de la experiencia real. Que sepamos, en ningún paŕs sudamericano, por ejemplo, los ciudadanos han sido llamados a participar de instancia alguna de constitución del poder, por más que en ciertos casos - como podría ser el del propio Ecuador seguramente han concurrido a las urnas tantas veces como un ciudadano inglés o alemán. En el plano económico, pongamos por caso, nadie les ha consultado sobre si están o no de acuerdo con la existencia de grandes monopolios que dominan la

En las llamadas transiciones pactadas hacia la democracia esta situación se torna más evidente aún: los políticos profesionales saben, mil veces mejor que el modesto profesor que escribe estas líneas, que no hay transición (a menos que fuera revolucionaria) que no implique un acuerdo previo con el poder. En el caso de Brasil, por ejemplo, eso se hizo, en palabras de José Alvaro Moisés (1987), a través de una "negociación informal, no explicita, y cuyos términos todavia no son enteramente conocidos del público". vida del país; tampoco, que se sepa, la población ha sido llamada a elegir

José Sarney, presidente do PDS, Antonio Carlos Magalhães, governador da Bahia e Jarbas Passarinho, presidente do Senado. Brasil, 1982 alibi - al gobierno como origen y no como culminación de un poder;

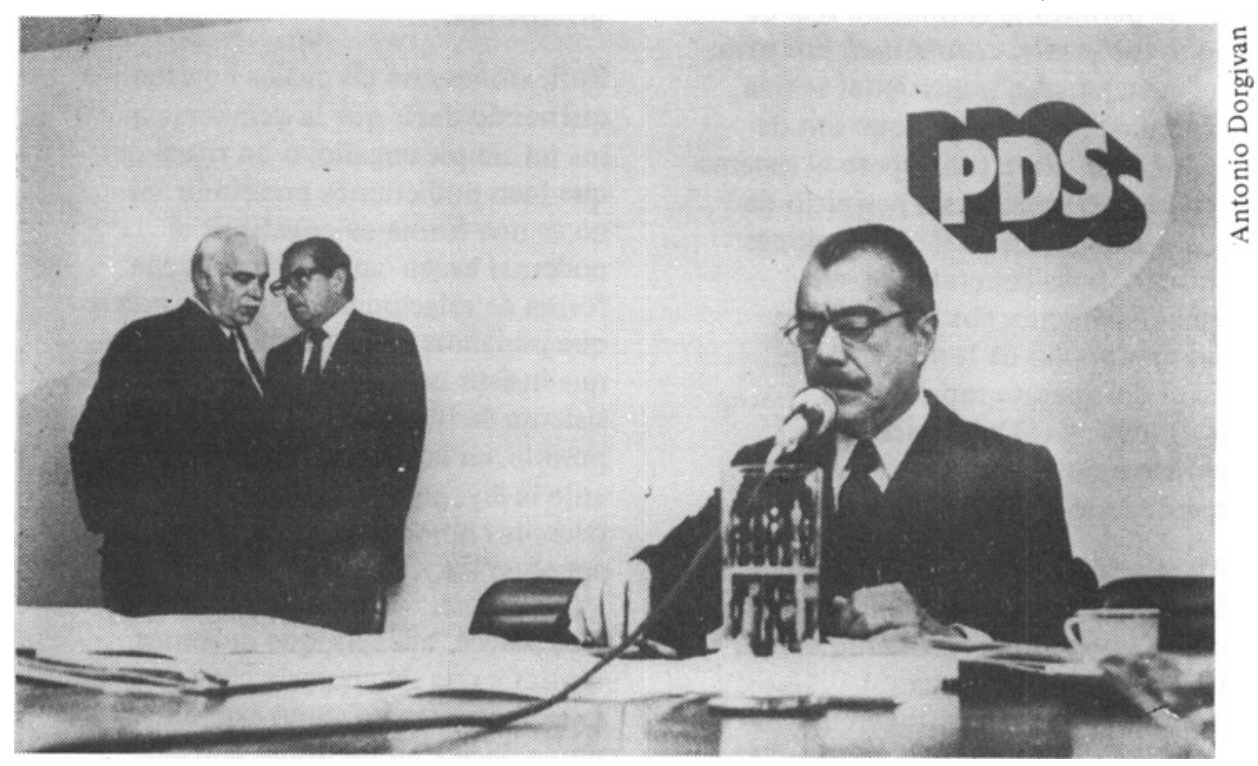

los propietarios y gerentes de fábricas, bancos, etcétera, cosa que tampoco se hace en los Estados Unidos (en rigor, es más fácil imaginar a los obreros rusos eligiendo a los directores de sus fábricas, hecho que ya está en estudio). En fin, no creo que los ciudadanos puedan in tervenir, a través del voto, en la estructuración o restructuración del poder militar. Cuando el pueblo ha intervenido en este ámbito, como en México, Bolivia, Cuba o Nicaragua, no ha sido precisamente por aquel medio.

Por eso, me parece que es más bien el poder, entendido como resultante de una estructura económica, social, política e ideológica determinada, el que interviene en la constitución de los ciudadanos-súbditos, y no a la inversa. Es dicho poder quien señala, para empezar, los lugares muchas veces falsos, engañosos, de constitución de sí mismo; es él el que muestra - otro

estudos AVANCADOS 
es él, en fin, quien interpela a los ciudadanos sobre lo que le interesa interpelarlos; él, quien decide sobre qué puntos los súbditos se han de pronunciar.

En las llamadas transiciones pactadas hacia la democracia esta situación se torna más evidente aún: los políticos profesionales saben, mil veces mejor que el modesto profesor que escribe estas líneas, que no hay transición (a menos que fuera revolucionaria) que no implique un acuerdo previo con el poder. En el caso de Brasil, por ejemplo, eso se hizo, en palabras de José Alvaro Moisés (1987), a través de una "negociación informal, no explicita, $y$ cuyos términos todavia no son enteramente conocidos del público".

El poder posee, como es obvio, sus secretos; pero de lo que no cabe duda es de que aquellas negociaciones tienen un límite reconocido de antemano: no se le puede pedir al poder que se autodesmantele con el fin de permitir la formación real de un nuevo poder, consensual. Por esto, las mencionadas transiciones se dan dentro de lineamientos que son de todos conocidos: (a) respeto al sistema economico vigente, sin perjuicio de que puedan hacerse modificaciones en sus formas concretas de funcionamiento; (b) legitimación del monopolio de la violencia en favor del aparato represivo ya instituido; y (c) adscripción permanente al mundo occidental, con todo lo que ello implica.

En relación a estas cuestiones, que tienen que ver con el poder más que con el gobierno propiamente dicho, las otras son relativamente subordinadas y constituyen un eventual objeto de negociación, dependiendo de cada correlación de fuerzas. En casos límites, como el de Haití (donde la transición no fue $\tan$ pactada que se diga, aunque sí supervisada por Estados Unidos), hubo incluso que ceder la cabeza de algunos tontons macoutes con tal de aplacar la furia popular y, sobre todo, de salvar la imagen y la integridad del aparato represivo más moderno, 0 sea, de las fuerzas armadas regulares. En Portugal, si mal no recuerdo, la sacrificada fue la policía política, igualmente. En Argentina, algunos generales han terminado en la prisión, pero más como chivos expiatorios de una guerra perdida que por su condición de torturadores. En cuanto al poder económico, lo que llama la atención en las transiciones democráticas contemporáneas es que, a diferencia de algunas anteriores

(Ecuador, 1944; República Dominicana, 1961, por ejemplo), esta vez no ha tenido que sacrificar absolutamente nada, ni siquiera de manera simbólica. La continuidad dictadura-democracia es, en este plano, inverosímil.

Reflexiones con las cuales no estamos queriendo decir que la democracia sea un simple engaño, $o$ un ritual del que bien pudiéramos prescindir. $\mathrm{Si}$ no es una forma de constituir el poder, sí es, en cambio, una buena forma de relacionarse con él: la mejor que podamos concebir. Por eso, hay que insistir en la defensa de un sistema de libertades 10 más amplio posible, en la igualdad irrestricta ante la ley, en el respeto de los derechos humanos por parte de aquel poder.

Nos parece, además, que debemos aspirar a una democracia cada día más transparente (como está de moda decir), en un doble sentido: primero, que los actos y decisiones 
de los gobernantes sean de inmediato conocimiento y fiscalización pública; y segundo, que la ciudadanía pueda pronunciarse de manera incquívoca sobre las cuestiones políticas verdaderamente fundamentales.

Recuerdo que, antes de ser aplastados por la represión de Víctor $\mathrm{Paz}$ Stenssoro (en una demostración de que "la democracia nos es sinónimo de relajo", según palabras de la revista brasileña Veja (1987), los mineros bolivianos intentaron realizar un plebiscito sobre el pago de la deuda externa, sobre el tipo de reformas económicas internas, etc. Banderas de este género deberían ser retomadas, hasta conseguir el establecimiento de consultas concretas que eviten sorpresas traumatizantes como la que la población del Brasil experiment 6 en noviembre de 1986 , cuando ni bien los votos se habian terminado de contar, que ya el gobierno aplicaba una política económica rigurosamente opuesta a la que implícitamente aprobara la mayoría abrumadora de los electores.
No digo que el poder constituido vaya a aceptar de inmediato este tipo de consultas, susceptibles de cuestionar no sólo los hábitos autoritarios (iojalá fuera sólo éso!), sino también algunos mecanismos normalizados de reproducción del sistema. Aún así, el intento tiene que ser realizado.

Al contrario de lo que el conservadurismo pregona, una política responsable no es la que se mueve siempre dentro de los estrechos límites marcados por la burguesía - además ocultándolos -, sino la que se encarga de mostrar al pueblo la estrechez clasista de tales límites. En este sentido, lo "pernicioso" no estriba, como piensa el profesor Hirschman, en exigir una democracia con crecimiento económico, mejor distribución del ingreso y autonomía nacional, sino en abandonar esas metas y dejar a nuestras jóvenes democracias (como $\tan$ tiernamente se las llama) a merced de los males que secularmente les han impedido prosperar en los países capitalistas subdesarrollados.

\section{Referências Bibliográficas}

Aumenta o interesse japonês no México. 1987. Folha de S. Paulo, 16 jun. p.A-11.

BARTRA, R. 1987. La jaula de la melancolia. Identidad y metamorfosis del mexicano. México, Enlace-Grijalbo.

BENEDETTI, M. \& VARGAS LLOSA, M. 1984. América Latina: los intelectuales y el subdesarrollo político. Vuelta. México, (92): 50, jul.

COUTINHO, C. N. 1984. A democracia como valor universal e outros ensaios. $2^{\text {a }}$ ed. ampliada, Rio de Janeiro, Salamandro.

DEBRAY, R. 1971. Conversación con Allende. México, Siglo XXI.

DREIFUSS, R. 1981. 1964: a conquista do Estado. Petrópolis, Vozes.

FURTADO, A. 1986. Dinámica socioeconómica de América Latina. Novos estudos CEBRAP, (14), fev.

GARCIA, M. A., org. 1986. As esquerdas e a democracia. São Paulo, Paz e Terra. 
GRAMSCI, A. 1975. Notas sobre Maquiavelo, sobre politica y sobre el Estado moderno. México, Juan Pablos.

HIRSCHMAN, A. O. 1986. La democracia en América Latina. Vuelta. México, (116): 28,jul.

KRAUZE, E. 1986. Por una democracia sin adjetivos.

LECHNER, N. 1985. Pacto social nos processos de democratização: a experiência latino-americana. Novos estudos CEBRAP. São Paulo, (13): 34, out.

MARTI, J. 1977. Nuestra América. In: - Política Nuestra América. México, Siglo XXI.

MOISÉS, J. A. 1987. Transição e negociação política. Folha de S. Paulo, 29 jun.

NADER,A.1987. Austeridade e p6: um plano que deu certo. Veja, (981):62,jun.

Novo salário mínimo é o mais baixo da história do país. 1987. Folha de S. Paulo, 16 jun.

Panorama económico de América Latina. 1987. El dia, México, 19 out. p. 22. Seccion: testimonios y documentos.

PRZEWORSKI, A. 1984. Ama a incerteza e serás democrático. Novos estudos CEBRAP. São Paulo, (9): 36, jul.

SANTOS, J. P. 1986. O que é pós-moderno. São Paulo, Brasiliense.

SINGER, P. 1978. Brazil: a country study. São Paulo, CEBRAP.

TOURAINE, A. 1982. El postsocialismo. Planeta. España.

1986. As possibilidades da democracia na América Latina. Revista brasileira de ciências sociais, 1(1): 12, jun.

UNICEF. 1987. Estado mundial de la Infancia. España. Siglo XXI.

VARAS, A. 1986. Fuerzas armadas y transición democritica en América del Sur. Material de Discusión. Programa FLACSO. Santiago de Chile. (1), octubre.

WEFFORT, F. C. 1986. Por que democracia . $4^{a} \mathrm{ed}$., São Paulo, Brasiliense.

\section{Bibliografia}

CARVALHO, J. M. 1987. Os bestializados. O Rio de Janeiro e a repriblica que não foi. Sāo Paulo, Cia. das Letras.

CASANOVA, P. G. 1965. La democracia en México. 1.a ed., México, Era.

CAVAROZZI, M. 1983. Autoritarismo y democracia. Buenos Aires, Centro Editor de América Latina.

CUEVA, A. 1987. Tiempos conservadores: America Latina en la derechización de Occidente. Quito, El Conejo.

FERNANDES, F. 1986. Que tipo de repuiblica. São Paulo, Brasiliense.

FLISFICH, N.; LBCHNER, N.; MOULIẢN, T. 1985. Problemas de la democracia y la política democrática en América Latina. In:FLISFICH, N. et alii. Demo 
cracia y desarrollo en América Latina. Buenos Aires, Grupo Editor Latinoamericano.

GERMANI, G.; TELLA, T. S.; IANNI, O. 1973. Populismo y contradicciones de clase en Latinoamérica. México, Era.

GILLESPIE, R. 1987. Soldados de Perón. Los Montoneros Buenos Aires, Grijalbo.

JAMESON, F. 1985. Pós-modernidade e sociedade de consumo. Novos estudos CEBRAP. São Paulo, (12): 16-26, junho.

LACLAU, E. 1978. Politica e ideologia en la teoría marxista. España, Siglo XXI.

LYOTARD, J. F. 1984. La condición postmoderna. Madrid, Cátedra.

MARINI, R.M. 1987. A nova democracia latino-americana.Humanidades Brasília, ano IV, maro-julho.

PETRAS, J. \& ZEITLIN, M. 1968. Latin America, reform or revolutions? New York, Fawcett Publications.

ROUQUIÉ, A. 1985. O mistério democrático das condições da democracia às democracias sem condiçбes. In: —— et alii. Como renascem as democracias. São Paulo, Brasiliense.

VATTINO, G. 1986. El fin de la modernidad. Nihilismo y hermenéutica en la cultura postmoderna. Mexico, Gedisa Editora.

\section{Agustín Cueva}

Agustín Cueva, 51, ć cientista polítıco, historiador, socıólogo e ensaísta, nasceu em Ibarra, no Equador. Entre seus principars livros estão: Entre la ira y la esperanza (1967), El proceso de dominación polttica en el Ecuador (1972, com onze edições em espanhol e tradução para o inglês), El desarrollo del capitalismo en América Latina, Prêmı Ensa1o do Editona! Siglo XXI, do Méxıco (1977, com dez edıçóes em espanhol c traduçōes para o japonês, holandês e português), Teorta social y procesos polfticos en A mérica Latina (México, 1979),

Lecturas y rupturas (Quito, 1986, dez ensaios sociológicos sobre a literatura do Equador). Autor de numerosos artigos em revistas especialızadas e obras coletivas da Aménca Latina, Estados Unidos, Europa e Canadá, é professor-tıtular da Facultad de Ciencias Políticas y Sociales da Universidad Nacional Autónoma de Méxıco e um dos coordenadores do

Centro de Estudios Latinoamericanos daquela Faculdade. Reconhecido por vános prêmios internacionais, professor e conferencista convidado em diversos centros universitários e membro-fundador da Associaçéo dos Historiadores da

América Latina e Caribe (ADHILAC), Agustín Cueva foi o primeiro professor-visitante do IEA em 1987, nos meses de maio e junho, contribuindo para a definiçáo do perfil acadêmico buscado pelo Instituto.

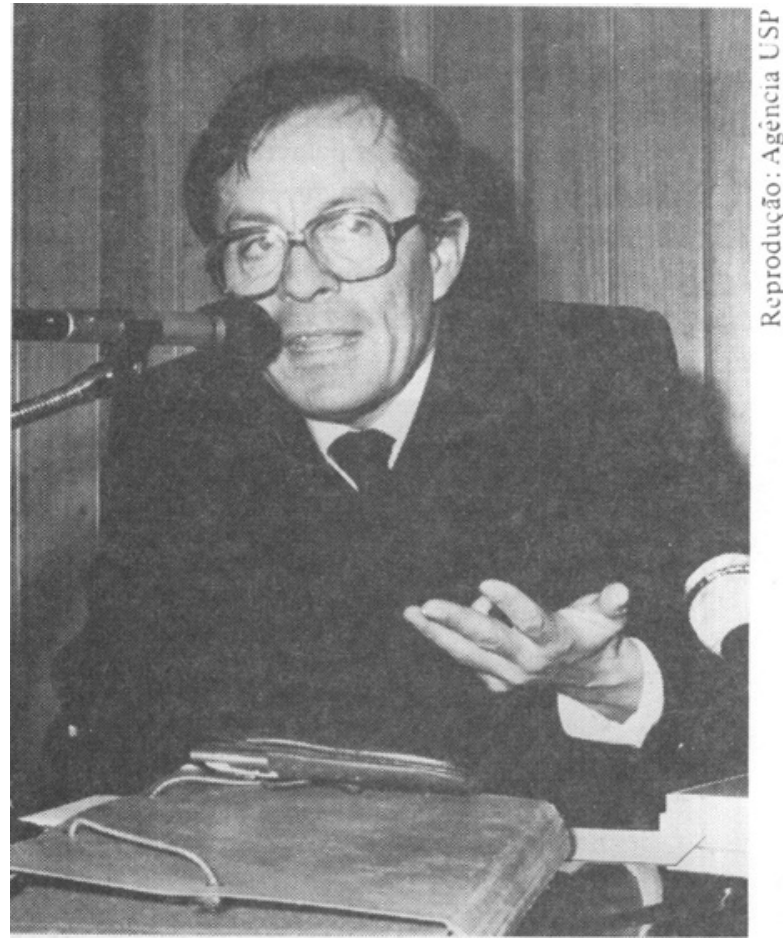

